\title{
Adjustment of Initial- and Terminal-Link Response Patterns to Suddenly Equivalent Terminal Links
}

\author{
Shrinidhi Subramaniam \\ West Virginia University
}

Follow this and additional works at: https://researchrepository.wvu.edu/etd

\section{Recommended Citation}

Subramaniam, Shrinidhi, "Adjustment of Initial- and Terminal-Link Response Patterns to Suddenly Equivalent Terminal Links" (2013). Graduate Theses, Dissertations, and Problem Reports. 190. https://researchrepository.wvu.edu/etd/190

This Thesis is protected by copyright and/or related rights. It has been brought to you by the The Research Repository @ WVU with permission from the rights-holder(s). You are free to use this Thesis in any way that is permitted by the copyright and related rights legislation that applies to your use. For other uses you must obtain permission from the rights-holder(s) directly, unless additional rights are indicated by a Creative Commons license in the record and/ or on the work itself. This Thesis has been accepted for inclusion in WVU Graduate Theses, Dissertations, and Problem Reports collection by an authorized administrator of The Research Repository @ WVU. For more information, please contact researchrepository@mail.wvu.edu. 
Adjustment of Initial- and Terminal-Link Response Patterns to Suddenly Equivalent Terminal Links

\author{
Shrinidhi Subramaniam \\ Thesis submitted to the Eberly College of Arts and Sciences \\ at West Virginia University \\ in partial fulfillment of the requirements for the degree of \\ Master of Science in \\ Behavior Analysis
}

\author{
Elizabeth Kyonka, Ph.D., Chair \\ Miranda Reed, Ph.D. \\ Claire St. Peter, Ph.D. \\ Department of Psychology
}
Morgantown, West Virginia
2013

Keywords: Choice; Timing; Rapid Acquisition; Concurrent Chains; Behavior in Transition, Pigeon

Copyright 2013 Shrinidhi Subramaniam 


\section{ABSTRACT \\ Adjustment of Initial- and Terminal-Link Response Patterns to Suddenly Equivalent Terminal Links}

Shrinidhi Subramaniam

Three pigeons were trained on concurrent-chain schedules. Concurrent variable-interval initial links produced fixed-interval (FI) terminal links. Occasional 'no-food' terminal links were interspersed pseudorandomly to obtain stop times, a single-trial measure of temporal discrimination. In rapid-acquisition conditions, terminal links were FI $10 \mathrm{~s}$ and FI $20 \mathrm{~s}$. Across sessions, the location of the initial link leading to the shorter terminal link varied pseudorandomly. Both terminal links were FI $15 \mathrm{~s}$ in a uniform condition. In the rapidacquisition conditions, initial-link response allocation tracked relative terminal-link immediacy and stop times tracked terminal-link FIs. Initial- and terminal-link pecking stabilized within the first half of sessions. By contrast, initial-link response allocation adjusted to FI 15-s terminal links in uniform sessions relatively gradually, only after several sessions. Although choice adjusted relatively slowly, stop times adjusted and stabilized within a few sessions for two out of three pigeons. Residuals from separate regressions of log initial-link response ratios and log stop time ratios on log terminal-link immediacy ratios were positively correlated in rapid-acquisition conditions but not systematically related in the uniform condition. This pattern of residual covariation indicates that the relation between mechanisms that determine choice and timing was moderated by environmental dynamics. 


\section{ACKNOWLEDGEMENTS}

I am grateful for the research support provided by the West Virginia University Department of Psychology Student Research Fund. A sincere thanks goes to my advisor, Dr. Elizabeth Kyonka, whose expertise and encouragement was indispensable. I would also like to thank my thesis committee members, Dr. Claire St. Peter and Dr. Miranda Reed, for emphasizing the importance of talking about basic behavioral research in an accessible way. Finally, I thank my family for their unwavering support. 


\section{TABLE OF CONTENTS}

Page

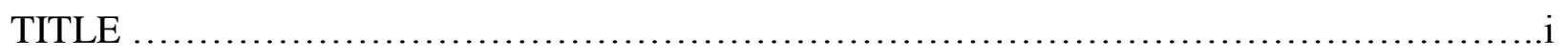

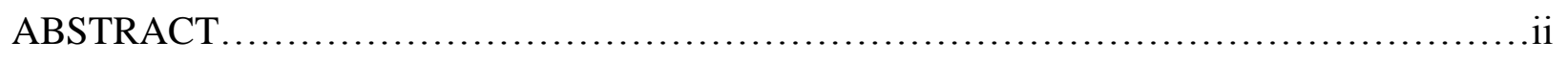

ACKNOWLEDGEMENTS ........................................................

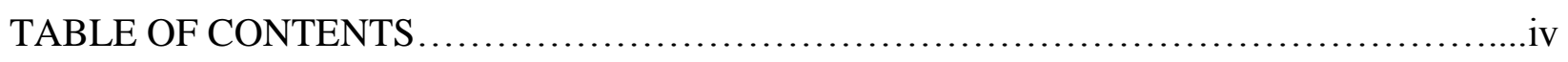

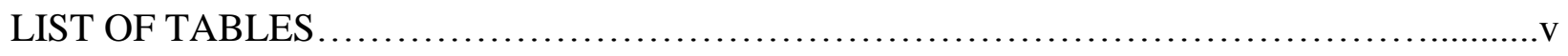

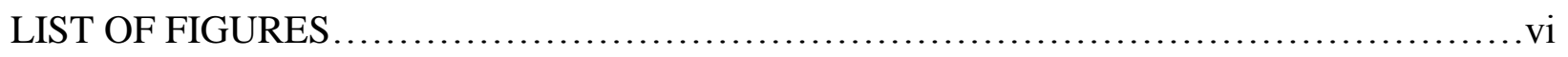

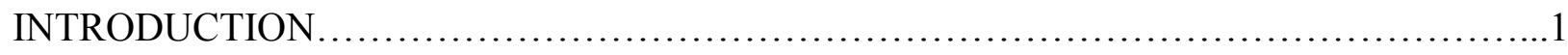

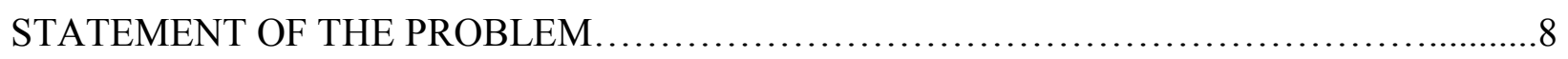

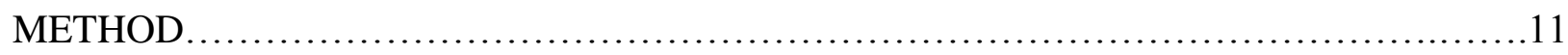

RESULTS................................................................ 15

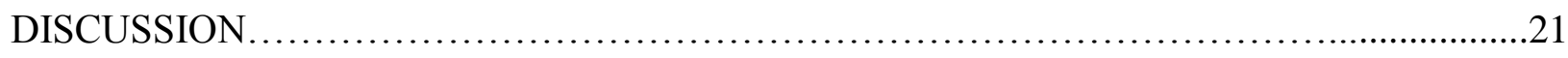

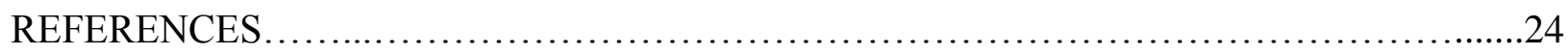

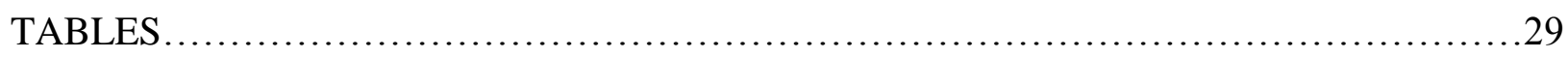

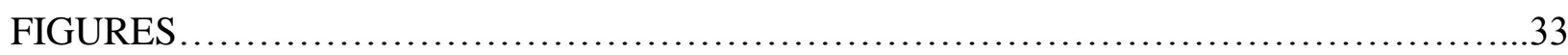

APPENDIX A, STABILITY ANALYSES FOR RAPID ACQUISITION ......................38

APPENDIX B, CHANGE POINT ANALYSIS.........................................45 


\section{LIST OF TABLES}

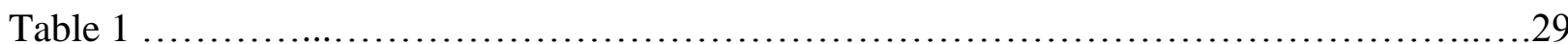

Equation 1 estimates

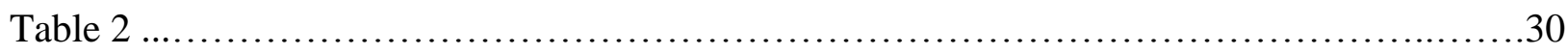

Descriptive statistics of stop times in rapid acquisition

Table 3 ...................................................................... 31

Results of single-sample t-tests comparing stop times in the uniform condition with rapidacquisition stop-time midpoints

Table 4

Individual-subject correlation coefficients from residual covariation analysis 


\section{LIST OF FIGURES}

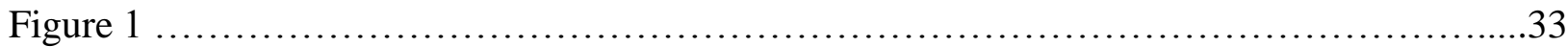

Diagram of concurrent-chain procedure

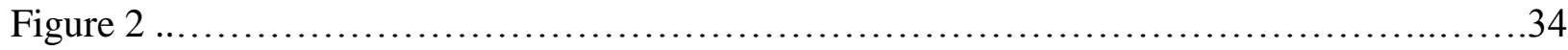

Stable estimates of choice as a function of session

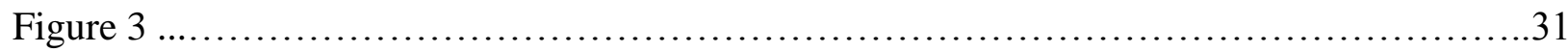

Stability analysis for the uniform condition

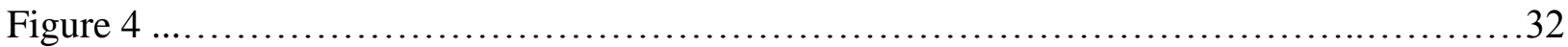

Stable estimates of timing as a function of session

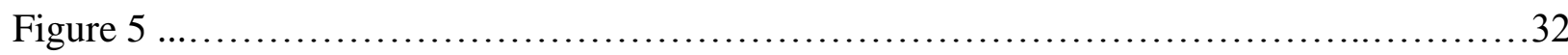

Residual covariation pooled across subjects 
Adjustment of Initial- and Terminal-Link Response Patterns to Suddenly Equivalent Terminal Links

Choice and timing are two ubiquitous behavioral processes. Choice is the allocation of time among sources of reinforcement. Timing refers to the stimulus control of behavior by the passage of time. Some theories of learning (e.g., Rate Estimation Theory; Gallistel \& Gibbon, 2000) assume that timing underlies all conditioning processes, including the adaptation of choice. In fact, impulsive choice is conceptualized as an operant class in which the estimation of reinforcer "value" is based on the learned or perceived time to reinforcement (e.g., delay discounting, Mazur, 1987). It follows that the processes of choice and timing are interdependent: Variability in timing should be related to variability in choice. Empirical demonstrations of the conditions under which choice and timing are interdependent or separate processes could inform theories of choice in general and, more specifically, theories of impulsive behavior that contribute to the understanding of societal problems such as substance abuse, obesity, and pathological gambling. These theories may have to be amended in certain circumstances if the assumed interdependence between choice and timing does not live up to rigorous experimental tests.

One way to determine the extent to which choice and timing are related is to measure the adjustment of response allocation and temporal discrimination to changes in the environment. Adjustment is one way to refer to the process by which behavior moves from a transition state to a steady state (Sidman, 1960). Sidman wrote that behavior in its steady state "does not change its characteristics over a period of time" (p. 234). A steady state is typically operationalized from researcher to researcher in terms of stability criteria. Although some decisions about data are based on specific training, stability criteria typically involve observations of behavior during 
some time window (e.g., a fixed number of sessions), and are informed by the variability and patterning of the data (Perone, 1991). Some researchers have attempted to quantify how choice adjusts or how preference is acquired (e.g., Mazur, 1995; Staddon, 1988), but examination of adjustment usually involves identifying the speed of transition into a steady state (Sidman, 1960). Questions can also be asked about the characteristics of behavior that change (e.g., variability and trend). Two points concerning the adjustment of timing and choice are pertinent to the current experiment: (1) Timing adjusts rapidly (e.g., Higa, 1996; Higa, Wynne, \& Staddon, 1991), and, (2) Over time, choice adjusts to “match" reinforcement parameters (Chung \& Herrnstein, 1967; Herrnstein, 1961).

\section{Timing Adjusts Rapidly}

The mere passage of time can serve as a stimulus that controls behavior (Dews, 1962). "Timing" refers to the stimulus control of behavior by the duration of events. Timing has been demonstrated using a variety of procedures (see Lejeune \& Wearden, 2006 for a review). A trialbased approach used to demonstrate temporal discrimination is the "peak procedure" (Catania, 1970; Roberts, 1981). This arrangement is a modification of a fixed-interval (FI) schedule. During most trials, a signal is initiated and the first response following the programmed delay is reinforced. No-food trials with the same stimulus arrangement, extended duration, and no programmed consequences for responding, are scheduled to occur occasionally throughout each session. Response distributions in these no-food trials can be described by Gaussian curves. The time at which the highest average rate of responding over the course of the session, or the peak of these distributions, falls near the time of the FI schedule value. The "peak time" and the spread of the distribution serve as measures of temporal discrimination. 
Peak times aggregated across many trials provide global measures of timing, but behavior in individual no-food trials can be examined to provide local estimates of temporal discrimination. Church, Meck, and Gibbon (1994) analyzed pigeon key pecks in individual nofood trials in the peak procedure. Pecking in individual trials conformed to a low-high-low pattern: The rate of pecks was low at the beginning of trials, high around the period of programmed food delivery, and low following that period. Church and colleagues identified two points of relatively abrupt transitions. The start time was the time that the high state began and the stop time was the time that it ended. The model was an exhaustive search (viz., the time of each peck in the trial was assigned as the start and stop time with some constraints) for a bestfitting index. The index, $A$, was maximized using the equation:

$$
A=d_{L 1}\left(r-r_{L 1}\right)+d_{H}\left(r_{H}-r\right)+d_{L 2}\left(r-r_{L 2}\right),
$$

where $r$ was the overall trial response rate, $r_{L 1}$ and $r_{L 2}$ were response rates during the first and second low states, $r_{H}$ was response rate during the high state, and the $d$ s were the durations of those high and low states. Start $\left(d_{L 1}\right)$ and stop $\left(d_{L 1}+d_{H}\right)$ times serve as measures of temporal discrimination that allow for inferences about the accuracy and precision of timing in individual trials.

Overall and within-session responding in FI schedules with and without no-food trials adjust to changes in schedule value rapidly. Higa (1996) and Higa, Wynne, and Staddon (1991) found rapid temporal control of wait times, or the latency to the first peck, when inter-food intervals in response-initiated FI schedules and time-based schedules were increased and decreased. Specifically, wait times adjusted to new interval durations within three exposures to that duration. To examine the rapid adjustment of timing in a peak procedure, Lejeune, Ferrara, Simmons, and Wearden (1997, Experiment 1) gave rats several sessions in a FI $20 \mathrm{~s}$ baseline, 
several cyclic transitions with fixed-interval delays of 10, 20, and 30 seconds, and a return to baseline. In all transitions, peak times tracked the schedule in effect, and were only slightly influenced by the previous-schedule delay. Taken together, the results from Higa, Lejeune, and colleagues suggest that the adjustment of timing following a change in the timed stimulus is almost immediately apparent.

\section{Response Allocation Adjusts to Match Reinforcement Parameters}

Choice is the allocation of time, effort or other resources among sources of reinforcement (Baum \& Rachlin, 1969). Given one source of reinforcement that is available after a short delay and another that is available following a longer delay, organisms will allocate more responses, and thus time, to the source that provides more immediate access to reinforcement (Chung \& Herrnstein, 1967). The generalized matching equation is a quantitative description of this relation (Staddon, 1968; Baum, 1974). It states that response allocation is a power function of relative reinforcement rates. In a review of 23 laboratory studies employing concurrent schedules (i.e., two independent schedules available simultaneously, where responding on one schedule has no effect on the other) the generalized matching equation accounted for over $90 \%$ of the variance in both responding to and time spent at a source of reinforcement (Baum, 1979).

Concurrent-chain schedules (Autor, 1960/1969) are one way to study choice between delayed reinforcers. The typical arrangement of concurrent chains involves concurrent variableinterval (VI)-VI initial links and an FI terminal link. The concurrent initial links are a choice phase in which the terminal link is the consequence. When one of the VI schedules operating in initial links is satisfied, initial links are suspended and the terminal-link FI associated with the satisfied initial link begins. Reinforcement is available for a response after a fixed interval has passed since terminal-link onset. For concurrent-chain schedules in which terminal-link delays 
determine rates of reinforcement, the generalized matching equation holds that initial-link response ratio is a power function of relative terminal-link immediacy (i.e., the reciprocal of delay). When response and immediacy ratios are log-transformed, the relation is linear. In an arrangement where the initial links are left and right operanda, generalized matching states that:

$$
\log \frac{B_{L}}{B_{R}}=\operatorname{alog} \frac{\left(\frac{1}{D_{L}}\right)}{\left(\frac{1}{D_{R}}\right)}+\log b
$$

where $B$ denotes response rate and $D$ denotes the terminal-link delay, with subscripts referring to the left and right alternatives. The terms $a$ and $b$ are empirically derived parameters that estimate sensitivity to the relative immediacy and bias for one alternative over another unaccounted for by immediacy, respectively.

The study of choice in dynamic environments involves varying parameters of reinforcement frequently; from session to session or within sessions. In these environments, response allocation adjusts rapidly to the changing contingencies. This rapid adjustment has been supported by research examining behavior in concurrent VI-VI schedules that were changed according to a pseudorandom binary sequence (PRBS; Hunter \& Davison, 1985; Schofield \& Davison, 1997). Grace, Bragason, and McLean (2003) used a PRBS in a concurrent-chain arrangement with pigeons to determine which initial link led to the shorter terminal link. Initial links were concurrent VI-VI schedules on the left and right keys in a three-key operant chamber. The terminal link was either a relatively short or long FI schedules on the center key. The initial link leading to the shorter terminal-link FI was changed pseudorandomly across sessions. Grace and colleagues analyzed response allocation in the initial links using an extension of the 
generalized matching law (Davison \& McCarthy, 1988) accounting for reinforcer immediacy ratios from nine previous sessions:

$$
\log \frac{B_{L n}}{B_{R n}}=a_{n} \log \frac{\left(\frac{1}{D_{L n}}\right)}{\left(\frac{1}{D_{R n}}\right)}+a_{n-1} \log \frac{\left(\frac{1}{D_{L(n-1)}}\right)}{\left(\frac{1}{D_{R(n-1)}}\right)}+\ldots+a_{n-9} \log \frac{\left(\frac{1}{D_{L(n-9)}}\right)}{\left(\frac{1}{D_{R(n-9)}}\right)}+\log b,
$$

Where variables $B$, and $D$, subscripts $L$ and $R$, and sensitivity and bias parameters $a$ and $b$ are the same as Equation 2. The subscript $n$ designated the current session, $n-1$ was the previous session, through $n-9$, or the ninth session before $n$. Fitting Equation 3 to response ratios from each session revealed that response ratios from session $n$ were controlled by the $n$ th-session immediacy ratio only; $a_{n}$ was significantly greater than zero for all pigeons but $a$ coefficients for all previous sessions were near zero and not systematically positive or negative. In this "rapid-acquisition" procedure, $\log$ response ratios tracked current-session reinforcer immediacy ratios.

\section{Convergent Measures of Timing and Choice}

Adjustment of the measures of temporal discrimination and response allocation can be examined within the same subjects in the same procedure. To obtain convergent measures of timing and choice, Grace and Nevin (1999) embedded no-food trials in FI terminal links of a concurrent chain (peak $+\mathrm{cc}$ ). They compared pigeon key pecks in an ABAB design with only a peak procedure in effect during the A phases and peak $+\mathrm{cc}$ in the B phases. Peak times in nofood trials were comparable in the two types of conditions. In the final B phase, terminal-link peak times adjusted to the change in FI schedule within two sessions, but response allocation in initial links adjusted gradually over 25 sessions. If responding in the initial links was a function of terminal-link immediacy, initial-link response ratios would have correlated with the conditioned value of those discriminative stimuli in the previous peak phase, but response ratios 
were consistent with the value of those stimuli in a much earlier condition. Grace and Nevin identified a potential dissociation in the mechanisms of choice and timing in the steady-state procedure.

Grace, Berg, and Kyonka (2006) used the peak + cc procedure to quantify the extent to which initial- and terminal-link behavior were related. Terminal-link FI schedules were $8 \mathrm{~s}$ and $16 \mathrm{~s}$ throughout the experiment. Initial links were either short or long. Initial-link response ratios differed depending on the duration of initial-link schedules, but start and stop times in peak trials were a function of the terminal-link FI schedule alone. Regression analyses revealed that changes in initial-link behavior (e.g., number of visits, pauses, response ratios) did not significantly predict any additional variance in behavior in no-food trials. Thus, Grace and colleagues concluded that choice and timing were clearly dissociated in this relatively stable environment.

To explore the relation between choice and timing in a more dynamic environment, Kyonka and Grace (2007) trained pigeons on a rapid-acquisition procedure with embedded nofood trials (an unpredictably changing peak $+c c$ ). Initial-link response ratios, start times, and stop times adjusted to terminal-link FIs by the second half of sessions. Kyonka and Grace determined the extent to which initial-link response ratios and start and stop times were related beyond current-session reinforcer immediacy using residual covariation analysis. First, they conducted separate regressions of log initial-link response ratios, log start-time ratios, and log stop-time ratios on log terminal-link immediacy ratios. Residuals obtained from those regressions represented variability in behavior not predicted by relative immediacy. They then correlated residuals from the initial-link response-ratio regression with those from start- and stop-time ratio regressions, thus quantifying the degree of interrelation between the remaining variability in response allocation and temporal discrimination. Residual correlations were small, 
but consistently positive. Kyonka and Grace concluded that choice and timing were mediated by errors in temporal discrimination, and hence, interdependent.

\section{Statement of the Problem}

Gallistel and Gibbon (2000) claimed that all conditioning processes are based on the learning of temporal intervals. If the claim is true, choice is timing. In apparent contradiction with this assumption, empirical demonstrations of the relation between response allocation and temporal discrimination have been mixed. In fact, there have been several steady-state experiments that suggest choice and timing are independent (Grace, Berg, \& Kyonka, 2006; Grace \& Nevin, 1999; Jozefowiez, Cerutti, \& Staddon, 2006). A series of rapid-acquisition experiments (Kyonka \& Grace, 2007, 2008, 2010), however, demonstrated positive evidence of interdependence through a method of converging operations (Garner, Hake, \& Eriksen, 1959). The primary objective of the present study was to determine the extent to which temporal dynamics control the interrelation of response allocation and temporal discrimination in concurrent-chain schedules.

Differences in the dependence of choice and timing found in previous research may be due to differences between the rapid-acquisition procedure and traditional steady-state concurrent-chains procedures for any of several reasons. Changing the programmed log immediacy ratios randomly each session in rapid acquisition could have produced residual covariation that is not present in steady-state data. It is possible that those pseudorandom changes amplify sources of error that are reduced by experimental control in the steady state. Frequency of schedule alternation has been shown to affect acquisition of choice (Gallistel, Mark, King, \& Latham, 2001) and timing (Higa, 1996; Higa, Wynne, \& Staddon, 1991; Lejeune, Ferrara, \& Wearden, 1997). 
The examination of initial- and terminal-link response patterns in changing environmental dynamics has been examined using the rapid-acquisition procedure. Kyonka, Subramaniam, and Grace (2013) trained pigeons to adjust to changes in the relative delay to reinforcement on a daily basis in a rapid-acquisition baseline. When both terminal-link delays were changed to an intermediate, equivalent interval in a transfer test for 11 sessions, preference (i.e., greater response allocation) for one of the two alternatives still developed even though start and stop times in no-food trials suggested strong temporal discrimination. Further, residual covariation of initial-link response ratios and stop time ratios was found in the rapid-acquisition baseline, but it was absent in the suddenly equivalent transfer test. The residual correlations from rapid acquisition were more frequently positive and statistically significant than the correlations from the suddenly equivalent condition when pooled across subjects. The findings from residual covariation could mean that the relation between choice and timing is interdependent in a variable environment and more independent in a transition to sudden equivalence.

Kyonka and Grace (2011) imposed several transitions from rapid acquisition to steady state using the same two reinforcer immediacy ratios in both conditions. The difference between rapid-acquisition and steady-state conditions was whether the initial link leading to the shorter terminal link was predictable from session to session. They found that initial-link response ratios in the beginning of sessions adjusted within a few exposures of the predictable schedule. Thus, transitioning from rapid acquisition to steady state does not necessarily lead to a failure to adjust choice.

In light of the systematic transitions observed in a similar procedure (Kyonka \& Grace, 2011), Kyonka, Subramaniam, and Grace's (2013) findings were baffling. Why did initial-link response ratios fail to adjust when start and stop times in the terminal links adjusted within a few 
sessions? Within-session acquisition of choice and within-session acquisition of timing were interdependent processes in the rapid-acquisition condition. Why did they apparently dissociate when terminal links became equivalent? The dissociation may have been an artifact of low statistical power in the residual covariation analyses due to the suddenly equivalent condition only being in effect for 11 sessions. It is first necessary to extend the suddenly equivalent condition for several sessions to achieve adequate comparisons between baseline and test conditions, and to replicate the rapid-acquisition baseline within subjects to rule out history or maturation effects.

In the current experiment, response allocation and stop times were examined in a transition from a rapid-acquisition procedure to a uniform condition in which red and green programmed terminal-link FIs were equated and were not changed across the condition. In rapid acquisition, terminal link FI delays were 10 and $20 \mathrm{~s}$, with the initial link leading to the shorter terminal link varying pseudorandomly from session to session. In the uniform condition, terminal-link delays were both FI 15 s. The main questions were: (1) do response allocation and temporal discrimination adjust to the intermediate, equivalent delays in the uniform condition following extensive training in rapid acquisition; (2) if so, how long does that adjustment take; and (3) does the covariation of log response ratios and log stop time ratios occur in rapidacquisition and uniform conditions? Based on previous research, it was hypothesized that response allocation and stop times would adjust by decreasing in variability over time, stop times would adjust at a faster rate than response allocation, and residual covariation would be found in the rapid-acquisition condition and be absent in the uniform condition, indicating that choice and timing were related in different ways in different environmental dynamics. 


\section{Method}

\section{Subjects}

Three pigeons were maintained at $85 \%$ ad libitum weight $\pm 15 \mathrm{~g}$ through postsession feedings, when appropriate. Pigeons were housed individually in a vivarium with a 12:12 hr light/dark cycle with free access to water. All pigeons had experience with rapid-acquisition concurrent chains in previous experiments.

\section{Apparatus}

Three standard three-key operant chambers, measuring $25.5 \mathrm{~cm}$ deep and $33.5 \mathrm{~cm}$ high, were used. The keys were spaced $6 \mathrm{~cm}$ apart and were positioned $24 \mathrm{~cm}$ above the floor. A force of approximately $0.15 \mathrm{~N}$ was required to register a response on any key. General illumination was provided by a house light located on the rear wall. Access to food (Nutriblend Pigeon Chow pellets) was available through a hopper, measuring $5.5 \mathrm{~cm}$ high and $6 \mathrm{~cm}$ wide and located 5.5 $\mathrm{cm}$ above the floor of the chamber. Chambers were housed in sound attenuated boxes with a ventilation fan to mask extraneous noises. Both data collection and experimental events were controlled by a MED-PC ${ }^{\circledR}$ program on a computer in an adjacent room.

\section{Procedure}

Because the pigeons were experienced with concurrent chains, training began immediately in a rapid-acquisition condition. Sessions were conducted daily at approximately 9AM for Pigeons 105 and 106 and 10:30 AM for Pigeon 108, with few exceptions. Sessions ended after 72 initial- and terminal-link cycles completed or 70 min elapsed, whichever came first. Figure 1 is a diagram of the initial- and terminal-link cycle in rapid acquisition. At the beginning of each cycle (i.e., trial), the side keys illuminated white signaling the VI 8-s initial links. A terminal-link entry was assigned pseudorandomly to the left or the right key with the 
constraint that in every block of 12 initial- and terminal-link cycles, 6 entries were assigned to each key. This dependent scheduling ensured that the pigeons obtained food from both terminallink schedules an equal number of times in each block of 12 cycles. During initial links, a peck produced a terminal-link entry if (a) it was made to the preselected key, (b) an interval from a VI 8-s schedule timed out, and (c) a 1-s changeover delay was satisfied (i.e., at least 1 s elapsed after a changeover to the side where terminal-link entry was arranged).

The initial-link schedule did not begin timing until a peck was made to either the left or right key. In this way, pausing following a terminal link was not recorded as time spent in the initial link. The VI 8-s schedule contained 12 intervals constructed from a geometric progression (Fleshler \& Hoffman, 1962). Separate lists were sampled without replacement such that all 12 intervals were used three times each for the left and right terminal links every session.

Entry into the terminal link was signaled by illumination of the center key either red or green, and darkening of the side keys. Whether the terminal link was red or green depended on which initial link was scheduled to produce it (red- left, green- right). Each session was divided into six blocks of twelve initial- and terminal-link cycles. Of the 12 cycles in each block, five were red food trials, five were green food trials, one was a red no-food trial, and one was a green no-food trial. Whether a terminal link ended with food or no food was determined pseudorandomly. On food trials, after the FI schedule elapsed, a peck to the center key was reinforced with 3-s access to food. During food delivery, all key lights and the house light were darkened and the hopper was raised and lighted. A 5-s limited hold was in effect: If no peck occurred within $5 \mathrm{~s}$ of the FI elapsing, the terminal link ended and no food was delivered. On nofood trials, the center key was lighted for $60 \mathrm{~s}$ and no food was delivered. 
The purpose of no-food trials was to obtain single-trial measures of temporal discrimination, namely, stop times. Stop times were calculated using the exhaustive search model described by Church, Meck, and Gibbon (1994) using Equation 1, with the constraint that the start time had to occur before the FI schedule value correlated with that terminal-link stimulus. For all trials, after a terminal link ended, the side keys were lighted white to signal the beginning of the next cycle of initial links.

The main independent variable was the dynamics of the programmed terminal-link immediacy ratios: These ratios were changed across sessions in rapid acquisition and remained the same in the uniform condition. Log immediacy ratios were calculated by dividing the immediacy for the red terminal link by the immediacy for the green terminal link, and calculating the logarithm of the obtained ratio. These calculations always resulted in log immediacy ratios of -0.3 and 0.3 in rapid acquisition, and 0 in the uniform condition. The dependent variables were $\log$ response ratios in the initial links, expressed as the logarithm of the number of left-key pecks divided by the number of right-key pecks, and stop times from no-food trials. Because one red and one green no-food terminal link were programmed to occur in each block, six start times and six stop times were recorded for each terminal link in every completed session. Since start times have been shown to be a less consistent measure of temporal control than stop times in rapidacquisition concurrent-chain schedules (Kyonka \& Grace, 2010), only stop times were analyzed in the present experiment.

All pigeons were trained extensively in rapid-acquisition condition in which the location of the initial link leading to the shorter terminal link was varied pseudorandomly from session to session. Whether the left or right initial link led to the FI 10-s terminal link was determined by a 31-step PRBS, with the other initial link leading to an FI 20-s terminal link. Following rapid 
acquisition, pigeons switched to a stable, uniform condition during which both terminal-link schedules were FI $15 \mathrm{~s}$, and terminal-link schedules remained the same until the stability criteria were satisfied. All pigeons were returned to rapid acquisition following the uniform condition when two stability criteria were met: (1) A minimum of 31 sessions (sample size analysis determined that 31 was the minimum number of sessions necessary to detect a correlation of $\rho=$ 0.1 with $80 \%$ power in residual covariation analyses); and (2) no monotonic trend in either positive or negative log response ratios over six sessions.

\section{Data Analysis}

Response allocation and temporal discrimination were analyzed at three temporal resolutions: Stable measures across sessions, blocks within sessions, and cycle by cycle. Regression analyses (Appendix A) confirmed that within session log response ratios and stop times stabilized at or before the second half of sessions in both rapid-acquisition conditions. Log response ratios in blocks 4-6 and the mean of the three stop times recorded in blocks 4-6 were within-session estimates of stable choice and temporal discrimination, respectively. These stable measures were used in the tracking analyses.

Blocks of twelve initial- and terminal-link cycles were the smallest units in this experiment in that could be directly compared. Each block consisted of five red and five green terminal links that ended with food reinforcement and one red and one green no-food terminal link. Thus, relative reinforcement rates were controlled experimentally for these blocks of 12 cycles, but not for smaller units. In a completed session there were six blocks from which one $\log$ initial-link response ratio, one left terminal-link stop time and one right terminal-link stop time were obtained. Analyses at the session block included assessments for stability in rapid acquisition (Appendix A) and residual covariation. 
At the highest temporal resolution, cycle-by-cycle, correlations of log response ratios with log immediacy ratios (Appendix A) and change points (Appendix B) were calculated. The cycle-by-cycle correlations contributed to assessments of stability in rapid-acquisition conditions. Change point analysis were used to identify whether and when in the session a switch to the preferred key occurred. The analyses were conducted on individual sessions in rapidacquisition and uniform conditions.

Unless otherwise specified, most analyses were conducted on the last 31 sessions of the rapid-acquisition condition for Pigeon 106, 32 sessions for Pigeon 105, and 33 sessions for Pigeon 108, and an equal number of sessions in the uniform condition. Following the uniform condition, all pigeons were returned to rapid acquisition for 31 sessions. Sessions in which $50 \%$ of initial- and terminal-link cycles were not completed were excluded from analyses.

\section{Results}

\section{Initial-Link Response Allocation}

To obtain parameters for sensitivity and bias in the rapid-acquisition conditions, Equation 2 was fit to $\log$ response ratios from the second half of sessions. Table 1 shows obtained parameters and goodness of fit for both rapid-acquisition conditions for each individual pigeon. In general, overmatching was observed. Sensitivity parameters were greater than one for all pigeons in both conditions with one exception: In the second rapid-acquisition condition, the estimate was 0.95 for Pigeon 105. For all pigeons, sensitivity decreased relative to initial rapid acquisition $(M=1.40, S D=0.19)$ in the rapid acquisition reversal $(M=1.18, S D=0.21)$. Across pigeons, sensitivity in was significantly lower than in the reversal than in the initial rapid acquisition condition, $t(2)=5.66, p<.05, d=3.44$, with a $95 \%$ confidence interval on the mean 
difference of 0.05 to 0.38 . Experience with the uniform condition weakened the relation between response allocation and relative immediacy found in rapid acquisition.

The sign of the bias parameter indicates the initial-link side key that is favored by each pigeon and the magnitude of the parameter indicates the amount of key bias. A positive bias parameter indicates bias for the left initial link and a negative parameter indicates bias for the right initial link. A left-key bias was observed for Pigeon 105 and right-key biases were observed for Pigeons 106 and 108 in both rapid-acquisition conditions. To determine whether the magnitude of the key bias changed, bias absolute values from the first and second rapidacquisition conditions were entered into a dependent-samples t-test. The difference between bias magnitudes in the first $(M=0.31, S D=0.02)$ and second $(M=0.29, S D=0.17)$ rapid acquisition conditions was not statistically significant, $t(2)=0.27, p=.82$, with $95 \%$ confidence intervals on the mean difference in magnitudes of -0.41 to 0.45 . Neither the valence nor the magnitude of side key bias changed over the course of the experiment.

One objective of the current experiment was to determine how initial-link response ratios adjusted when the programmed terminal-link immediacy ratios stopped changing pseudorandomly from session to session. Figure 2 shows log response ratios for each pigeon for all conditions of the experiment. Each data point represents response allocation from the second half of a single session. With few exceptions, log response ratios tracked log immediacy ratios in rapid-acquisition conditions. In the first 15 sessions of the uniform condition, log response ratios varied, but corresponded with the sign of rapid acquisition key bias (left, right and right) in 12/15, 12/15 and 10/15 sessions for Pigeons 105, 106 and 108, respectively. After 15 sessions of the uniform condition, log response ratios were less variable and the sign of the log response ratio corresponded with the sign of the bias parameter in $96.06 \%$ of sessions across all pigeons. 
This increase in correspondence between the sign of log response ratios and bias parameters provides evidence that log response ratios in the second half of sessions in the uniform condition adjusted by approaching an individually determined indifference point.

To determine when response allocation stabilized in the uniform condition, an analysis of the moving-average variability of $\log$ response ratios was used. Variability was measured using the standard deviation of log response ratios from the current session and six previous sessions. The session in which adjustment occurred was defined as the first of three consecutive sessions during which variability was within one standard deviation of the minimum value observed in the moving average. Figure 3 shows the moving-average variability as a function of session in the uniform condition for individual pigeons, as well as the session in which log response ratios adjusted. Log response ratios adjusted during session 22 of the uniform condition for Pigeons 105 and 108, and session 15 of the uniform condition for Pigeon 106. Whereas stability analyses in rapid acquisition determined that response allocation adjusted within single sessions, it took over two weeks for response allocation to stabilize in the uniform condition.

\section{Terminal-Link Stop Times}

Stability analyses were conducted to confirm that stop times adjusted within sessions in rapid-acquisition condition. Appendix A shows stability analyses for stop times in rapid acquisition: Stop times adjusted within the first half of sessions in rapid acquisition, and sensitivity of stop times to the FI schedule value increased over blocks within sessions. Figure 4 shows stable within-session stop times. Each data point represents the mean of stop times from the second half of a session (i.e., from the fourth, fifth, and sixth no-food terminal links). Table 2 shows stop times for each schedule value of rapid-acquisition conditions for individual pigeons. In rapid acquisition, stop times tracked the terminal-link FI: Stop times were shorter when the FI 
schedule value was shorter. Averaged across replications of rapid acquisition and then across pigeons, stable stop times were $18.57(S E=0.59)$ for the FI $10 \mathrm{~s}$ terminal link, and $28.74(S E=$ 0.73) for the FI $20 \mathrm{~s}$ terminal link.

Another objective in conducting this experiment was to determine the point at which stop times adjusted in the uniform condition. Analyses of the moving-average variability of log stop time ratios (Kyonka \& Grace, 2007) were conducted to identify the session during which stop times stabilized in the uniform condition. Log stop-time ratios, $\left(\log \left(1 / \mathrm{Stop}_{\mathrm{Red}}\right) /\left(1 / \mathrm{Stop}_{\mathrm{Green}}\right)\right)$, served as a relative measure of timing. Variability was measured using the standard deviation of $\log$ stop-time ratios from the current session and six previous sessions. The session in which adjustment occurred was defined as the first of three consecutive sessions during which variability was within one standard deviation of the minimum value observed in the moving average. This stability criterion enabled direct comparisons of sessions to stability for both the dependent variables (i.e., response allocation and temporal discrimination). Figure 3 shows the moving-average variability as a function of session in the uniform condition for individual pigeons, as well as the session in which log stop-time ratios adjusted. Log stop-time ratios adjusted during session 16 of the uniform condition for Pigeon 105, session 29 of the uniform condition for Pigeon 106, and session 7 of the uniform condition for Pigeon 108. Stop times adjusted more quickly than log response ratios for two out of three pigeons.

To explore how stop times stabilized in the uniform condition, log stop-time ratios were analyzed to determine whether stop times became equivalent to each other (i.e., red stop time $=$ green stop time). Single-sample $t$ tests were used to test the null hypothesis that stable log stoptime ratios in the uniform condition (i.e., ratios following the session identified in the previous analysis) were equal to zero for each individual pigeon. For all pigeons, log stop-time ratios did 
not significantly differ from zero: Pigeon $105, t(16)=-0.48, p>.05, d=-0.12$, with $95 \%$ confidence limits on the mean from -0.03 to 0.02 ; Pigeon $106, t(2)=0.57, p>.05, d=0.33$, with $95 \%$ confidence limits on the mean from -0.13 to 0.17 ; Pigeon $108, t(25)=-0.32, p>.05, d=-$ 0.06, with $95 \%$ confidence limits on the mean from -0.02 to 0.02 . Stop times stabilized in the uniform condition by becoming equivalent on the red and green terminal links.

To further examine how stop times stabilized in the uniform condition, single-sample $t$ tests were used to determine whether stop times in the uniform condition became equivalent to the midpoint of means from the previous rapid-acquisition condition. The null hypothesis was that stable stop times toward the red and green terminal links in the uniform condition equaled the mean of stable stop times toward the FI 10 s and FI 20 s terminal links in the initial rapidacquisition condition. Table 3 lists the results of these single-sample $t$ tests along with descriptive statistics. For Pigeons 105 and 106, red and green stable stop times in the uniform condition were not significantly different than the midpoint of the means in rapid acquisition. For Pigeon 108, red and green stable stop times in the uniform condition were slightly lower than the midpoint of means in rapid acquisition, though the effect size was small. For two out of three pigeons, stop times stabilized by becoming similar to the average obtained stop times in rapid acquisition.

\section{Residual Covariation of Choice and Timing}

To determine whether the residual covariation of choice and timing was present in rapid acquisition and uniform conditions, residual covariation analyses of log initial-link response and log stop-time ratios were conducted for all conditions. For each pigeon, relative measures of choice and timing were obtained by computing $\log$ response ratios $\left(\log \mathrm{B}_{\mathrm{L}} / \mathrm{B}_{\mathrm{R}}\right)$ and $\log$ stop-time ratios $\left(\log \left(1 /\right.\right.$ Stop $\left._{\text {Red }}\right) /\left(1 /\right.$ Stop $\left.\left._{\text {Green }}\right)\right)$ for each block of 12 initial- and terminal-link cycles within 
sessions. Separate regressions of log initial-link response ratios and log terminal-link stop-time ratios on log immediacy ratios were conducted for each block. Residuals obtained from regressions of $\log$ response ratios on log immediacy were correlated with those obtained from regressions of log stop-time ratios on log immediacy for each block. These correlations were a quantitative estimate of the relation between variance in log response ratios and log stop-time ratios not attributable to terminal-link immediacy.

Table 4 shows correlations between residuals for log response ratios and log stop-time ratios in the rapid-acquisition and uniform conditions for each pigeon. In initial rapid acquisition, $100 \%$ of residual correlations were positive and five out of 18 correlations were statistically significant. In the uniform condition, $78 \%$ of correlations were positive and only one was statistically significant. Upon returning to rapid acquisition, $94 \%$ of correlations became positive and nine were statistically significant. Figure 5 shows residual correlations pooled across pigeons. When residuals were pooled across pigeons, correlation coefficients from each block within sessions of the uniform condition were lower than those obtained in the corresponding blocks within sessions of the rapid-acquisition reversal.

To compare the obtained correlations statistically, individual-subject correlation coefficients were entered into a repeated measures analysis of variance (ANOVA) with Condition as the factor. The ANOVA revealed that correlations differed between conditions, $F(2,30)=6.82, p<.01, \eta_{\mathrm{P}}^{2}=.31$. Post-hoc tests indicated that residual correlations were significantly higher in the rapid-acquisition conditions $(M=.23, S D=.17 ; M=.31, S D=.16)$ than the uniform condition $(M=.10, S D=.16)$. Thus, residual covariation revealed that errors in temporal discrimination were related to errors in choice to a greater degree in rapid acquisition than in the uniform condition. 


\section{Discussion}

It has been suggested that, when the environment shifts from one that is frequently changing to one that stays the same, temporal discrimination adjusts, but choice does not (Kyonka, Subramaniam, \& Grace, 2013). The current experiment was designed to examine choice (log response ratios) and timing (stop times in no-food trials) in a transition from rapid acquisition, in which relative time to food was pseudorandomly determined, to a uniform condition in which relative time to food remained constant and intermediate to that in rapid acquisition. It was found that, for two out of three pigeons, choice took longer to adjust than timing. Stability in log response ratios took 22 sessions for Pigeons 105 and 108. Temporal control of stop times more rapidly adjusted to the terminal-link schedules for those two pigeons, reaching stability criteria within 7 and 16 sessions. For Pigeon 106, log response ratios adjusted within 15 sessions of the uniform condition. Choice adjusted relatively quickly, but temporal control of stop times did not occur until session 29 of the uniform condition.

One avenue that was used to determine whether choice and timing were interdependent or dissociated was through residual covariation analysis. Log response and log stop-time ratio residuals covaried in rapid acquisition. Variance in choice not attributable to the relative time to reinforcement was positively correlated with variance in timing not attributable to relative time to reinforcement. This covariation failed to persist in the same magnitude during the uniform condition. Thus, the literature indicating dissociation in steady state procedures (e.g., Grace, Berg, \& Kyonka, 2006; Grace \& Nevin, 1999; Jozefowiez, Cerutti, \& Staddon, 2006) can be synthesized with the literature indicating interdependence in frequently changing environments (e.g., Kyonka \& Grace, 2007, 2008, 2010). Environmental dynamics are an important variable, perhaps moderating the interrelation between choice and timing. 
The inverse relation between sensitivity to terminal link immediacy and adjustment rates of choice and timing was an interesting finding in the current experiment. In general, it has been suggested that temporal control adjusts rapidly (Higa, 1996; Higa, Wynne, \& Staddon, 1991). However, stop times for one pigeon (106) did not adjust until session 29 of the uniform condition, while response allocation adjusted at session 15. In contrast, when stop times adjusted immediately, choice was slow to adjust (Pigeons 105 and 108). This finding was similar to those of Kyonka, Subramaniam, and Grace (2013), in which the weakest temporal control of stop times was paired with evidence of the strongest adjustment of choice. One reason for these counterintuitive findings is that inconsistent response patterns (and generally low rates of pecking) in no-food trials correlated with FI schedules may have led to artifactually weak temporal discrimination for these two pigeons (106 in the current experiment and 167 in Kyonka and colleagues' study). Different variables indicating temporal discrimination (e.g., responding in FI trials, peak times, pauses) may be better markers of the learned time to reinforcement. More experimental evidence is needed to test the concurrent validity of different measures of temporal discrimination, and assess why weak temporal control was paired with adaptable choice in the current experiment.

Something about the uniform $15 \mathrm{~s}$ FI schedule value may have led to the relatively slow adjustment of choice. This lack of adjustment was not evident when FI schedule values were kept constant in a stable condition with a log immediacy greater to or less than zero (see Kyonka \& Grace, 2011). Temporal bisection methods involve reinforcement of the discrimination between a "short" (S) and "long" (L) fixed time interval with embedded probe trials of intermediate durations (Stubbs, 1968). Church and Deluty (1977) used a temporal bisection procedure with probe trials of intermediate durations in which responding was not reinforced. 
The point of bisection, or subjective equality, between two intervals tracked the geometric mean, or square root of the product of the two extreme intervals. From this finding it can be inferred that an intermediate delay at the geometric mean is subjectively as long as the L interval and as short as the $\mathrm{S}$ interval. Therefore, the relatively slow adjustment of response allocation found in the transition from rapid-acquisition to the uniform condition may have resulted from the intermediate delay being sampled from the range of experience.

The current experiment is limited in that only one uniform condition was assessed. Future investigations on the adjustment of choice and timing in concurrent chains could vary the time to reinforcement in the terminal links across several uniform conditions. These uniform schedules could sample from experienced delays or be entirely novel. For example, FI $5 \mathrm{~s}$ or FI $45 \mathrm{~s}$ terminal links in the arrangement used in the current experiment may impact the adjustment of choice and timing. Something akin to the "terminal-link effect" might occur in which preference for the initial link correlated with the shorter terminal link increases with increased absolute duration of the terminal links (e.g., MacEwen, 1972; Williams \& Fantino, 1978). Not only could the adjustment of choice occur at different rates, the biases found in log response ratios in the current experiment may become more extreme if the terminal links were longer FI schedules. In sum, models of intertemporal choice may take for granted that choice and timing are the same processes. The clear dissociation between initial- and terminal-link pecking found in the uniform condition in the current experiment indicated that the acquisition of choice and timing were not governed by the same mechanisms. Errors in the subjective time to reinforcement did not clearly relate to errors in choice. Models of impulsive choice should take into account environmental dynamics. The relative utility of examining impulsive choice using one or separate parameters for choice and timing in different dynamics should be assessed. 


\section{References}

Autor, S. M. (1960/1969). The strength of conditioned reinforcers as a function of frequency and probability of reinforcement. In D. P. Hendry (Ed.), Conditioned Reinforcement. (pp. 237-162) Homewood, Illinois: The Dorsey Press.

Baum, W. M. (1974). On two types of deviation from the matching law: Bias and undermatching. Journal of the Experimental Analysis of Behavior, 22(1), 231-242. doi: 10.1901/jeab.1974.22-231

Baum, W. M. (1979). Matching, undermatching, and overmatching in studies of choice. Journal of the Experimental Analysis of Behavior, 32(2), 269-281. doi: 10.1901/jeab.1979.32-269

Baum, W. M., \& Rachlin, H. C. (1969). Choice as time allocation. Journal of the Experimental Analysis of Behavior, 12(6), 861-874. doi: 10.1901/jeab.1969.12-861

Catania, A. C. (1970). Reinforcement schedules and psychophysical judgments. In W. N. Schoenfeld (Ed.), Theory of reinforcement schedules (pp. 1-42). New York: AppletonCentury- Crofts.

Chung, S. H., \& Herrnstein, R. J. (1967). Choice and delay of reinforcement. Journal of the Experimental Analysis of Behavior, 10(1), 67-74. doi: 10.1901/jeab.1967.10-67

Church, R. M., \& Deluty, M. Z. (1977). Bisection of temporal intervals. Jounal of Experimental Psychology: Animal Behavior Processes, 3(3), 216-228. Retrieved from: http://www.ncbi.nlm.nih.gov/pubmed/881613

Church, R. M., Meck, W. H., \& Gibbon, J. (1994). Application of scalar timing theory to individual trials. Journal of Experimental Psychology: Animal Behavior Processes, 20 (2), 135-155. doi: 10.1037/0097-7403.20.2.135 
Davison, M., \& McCarthy, D. (1988). The Matching law: A research review. Hillsdale, NJ: Lawrence Erlbaum Associates.

Dews, P. B. (1962). The effect of multiple $S^{\Delta}$ periods on responding in a fixed-interval schedule. Journal of the Experimental Analysis of Behavior, 5(3), 369-374. doi: 10.1901/jeab.1962.5-369

Fleshler, M., \& Hoffman, H. S. (1962). A progression for generating variable-interval schedules. Journal of the Experimental Analysis of Behavior, 5(4), 529-530. doi:

10.1901/jeab.1962.5-529

Gallistel, C. R., \& Gibbon, J. (2000). Time, rate, and conditioning. Psychological Review, 107(2), 289-344. doi: 10.1037//0033-295X.107.2.289

Gallistel, C. R., Mark, T. A., King, A. P., \& Latham, P. E. (2001). The rat approximates an ideal detector of changes in rates of reward: Implications for the law of effect. Journal of Experimental Psychology: Animal Behavior Processes, 27(4), 354-372. doi: 10.1037//0097-7403.27.4.354

Garner, W. R., Hake, H. W., \& Eriksen, C. W. (1956). Operationism and the concept of perception. Psychological Review, 63(3), 149-159. doi: 10.1037/h0042992

Grace, R. C., Berg, M. E., \& Kyonka, E. G. E. (2006). Choice and timing in concurrent chains: Effects of initial-link duration. Behavioural Processes, 71(2), 188-200. doi: 10.1016/j.beproc.2005.11.002

Grace, R. C., Bragason, O., \& McLean, A. (2003). Rapid acquisition of preference in concurrent chains. Journal of the Experimental Analysis of Behavior, 80(2), 235-252. doi: 10.1901/jeab.2003.80-235 
Grace, R. C., \& Nevin, J. A. (1999). Timing and choice in concurrent chains. Behavioral Processes, 45(1), 115-127. doi: 10.1016/S0376-6357(99)00013-3

Herrnstein, R. J. (1961). Relative and absolute strength of a response as a function of frequency of reinforcement. Journal of the Experimental Analysis of Behavior, 4(3), 267-272. doi: 10.1901/jeab.1961.4-267

Higa, J. J. (1996). Rapid timing of a single transition in interfood interval duration by rats. Animal Learning \& Behavior 25(2), 177-184. doi: 10.3758/BF03199056

Higa, J. J., Wynne, C. D., \& Staddon, J. E. R. (1991). Dynamics of time discrimination. Journal of Experimental Psychology: Animal Behavior Processes, 17(3), 281-291. doi: 10.1037/0097-7403.17.3.281

Hunter, I., \& Davison, M. (1985). Determination of a behavioral transfer function: White-noise analysis of session-to-session response-ratio dynamics on concurrent VI VI schedules. Journal of the Experimental Analysis of Behavior, 43(1), 43-59. doi:

10.1901/jeab.1985.43-43

Jozefowiez, J., Cerutti, D. T., \& Staddon, J. E. R. (2006). Timescale invariance and Weber's Law in choice. Journal of Experimental Psychology: Animal Behavior Processes, 32(3), 229-238. doi: 10.1037/0097-7403.32.3.229

Kyonka, E., \& Grace, R. C. (2007). Rapid acquisition of choice and timing in pigeons. Journal of Experimental Psychology: Animal Behavior Processes, 3 (4), 392-408. doi: 10.1037/0097-7403.33.4.392

Kyonka, E., \& Grace, R. C. (2008). Rapid acquisition of preference in concurrent chains when alternatives differ on multiple dimensions of reinforcement. Journal of the Experimental Analysis of Behavior, 89(1), 49-69. doi: 10.1901/jeab.2008.89-49 
Kyonka, E., \& Grace, R. C. (2010). Rapid acquisition of choice and timing and the provenance of the terminal-link effect. Journal of the Experimental Analysis of Behavior, 94(2), 209225. doi: 10.1901/jeab.2010.94-209

Kyonka, E., \& Grace, R. C. (2011). Transitions between unpredictably changing and unchanging terminal-link immediacy ratios have differential effects on response allocation at the beginnings and ends of sessions. Poster session presented at the meeting of the Society for the Quantitative Analysis of Behavior, Denver, CO.

Kyonka, E., Subramaniam, S., \& Grace, R. C. (2013). Adjustment of initial- and terminal-link responding to suddenly equivalent terminal links. Manuscript in preparation.

Lejeune, H., Ferrara, A., Simons, F., \& Wearden, J. H. (1997). Adjusting to changes in the time of reinforcement: Peak-interval transitions in rats. Journal of Experimental Psychology: Animal Behavior Processes, 23(2), 211-231. doi: 10.1037//0097-7403.23.2.211

Lejeune, H., \& Wearden, J. H. (2006). Scalar properties in animal timing: Conformity and violations. The Quarterly Journal of Experimental Psychology, 59(11), 1875-1908. doi: $10.1080 / 17470210600784649$

MacEwen, D. (1972). The effects of terminal-link fixed-interval and variable-interval schedules on responding under concurrent chained schedules. Journal of the Experimental Analysis of Behavior, 18, 253-261. doi: 10.1901/jeab.1972.18-253

Mazur, J. E. (1987). An adjusting procedure for studying delayed reinforcement. In M. L. Commons, J. E. Mazur, J. A. Nevin, \& H. Rachlin (Eds.), Quantitative analysis of behavior: The effect of delay and of intervening events on reinforcement value (pp. 5573). Hillsdale, NJ: Erlbaum. 
Mazur, J. E. (1995). Development of preference and spontaneous recovery in choice behavior with concurrent variable-interval schedules. Animal Learning and Behavior, 23(1), 93103. doi: $10.3758 / \mathrm{BF} 03198020$

Perone, M. (1991). Experimental design in the analysis of free-operant behavior. In A. Lattal \& I. Iverson (Eds.), Experimental analysis of behavior, Part I (pp. 135-168). New York, NY: Elsevier Science.

Roberts, S. (1981). Isolation of an internal clock. Journal of Experimental Psychology: Animal Behavior Processes, 7(3), 242-268. doi: 10.1037/0097-7403.7.3.242

Sidman, M. (1960). Tactics of scientific research. Oxford England: Basic Books.

Schofield, G., \& Davison, M. (1997). Nonstable concurrent choice in pigeons. Journal of the Experimental Analysis of Behavior, 68(2), 219-232. doi: 10.1901/jeab.1997.68-219

Staddon, J. E. R. (1968). Spaced responding and choice: A preliminary analysis. Journal of the Experimental Analysis of Behavior, 11(6), 669-682. doi: 10.1901/jeab.1968.11-669.

Staddon, J. E. R. (1988). Quasi-dynamic choice models: melioration and ratio-invariance. Journal of the Experimental Analysis of Behavior, 49(2), 303-320. doi: 10.1901/jeab.1988.49-303

Stubbs, A. (1968). The discrimination of stimulus duration by pigeons. Journal of the Experimental Analysis of Behavior, 11, 223-238. doi: 10.1901/jeab.1968.11-223

Williams, B. A., \& Fantino, E. (1978). Effects on choice of reinforcement delay and conditioned reinforcement. Journal of the Experimental Analysis of Behavior, 29, 77-86. doi: 10.1901/jeab.1978.29-77 
Table 1

\begin{tabular}{ccccc}
\hline Pigeon & Rapid Acquisition & Sensitivity $(a)$ & Bias $(b)$ & VAC \\
\hline 105 & First & 1.18 & 0.31 & 0.61 \\
& Second & 0.95 & 0.48 & 0.38 \\
106 & First & 1.49 & -0.33 & 0.85 \\
& Second & 1.22 & -0.24 & 0.61 \\
108 & First & 1.51 & -0.30 & 0.65 \\
& Second & 1.37 & -0.14 & \\
\hline
\end{tabular}

Note: Estimates derived from fitting Equation 1 to $\log$ response ratios for each individual pigeon during the first and second rapid-acquisition conditions. 
Table 2

\begin{tabular}{cccc}
\hline Pigeon & Rapid Acquisition & $\begin{array}{c}\text { Stop Time } \\
\text { FI 10 s (SD) }\end{array}$ & $\begin{array}{c}\text { Stop Time } \\
\text { FI 20 s (SD) }\end{array}$ \\
\hline 105 & First & $17.10(6.53)$ & $28.15(5.14)$ \\
& Second & $18.07(5.74)$ & $29.47(4.05)$ \\
106 & First & $19.35(8.04)$ & $26.41(8.77)$ \\
& Second & $19.87(4.42)$ & $29.29(3.68)$ \\
& First & $17.99(4.35)$ & $29.74(3.73)$ \\
& Second & $19.01(4.06)$ & $29.35(3.74)$ \\
\hline
\end{tabular}

Note: Mean stable stop times (and standard deviations) are shown for each FI schedule value and rapid-acquisition condition for individual pigeons. 
Table 3

\begin{tabular}{|c|c|c|c|c|c|c|c|c|}
\hline Pigeon & $\mu$ & TL & $\begin{array}{c}\text { Mean Stop Time } \\
(S D)\end{array}$ & $\mathrm{df}$ & $t$ & $p$ & $d$ & $95 \% \mathrm{CIs}$ \\
\hline \multirow[t]{2}{*}{105} & 22.55 & Red & $22.29(1.54)$ & 16 & -0.69 & .50 & -0.17 & $21.50,23.08$ \\
\hline & & Green & $22.04(1.61)$ & 16 & -0.48 & .22 & -0.31 & $21.21,22.87$ \\
\hline \multirow[t]{2}{*}{106} & 22.88 & Red & $22.43(6.57)$ & 2 & -0.12 & .92 & -0.07 & $6.09,38.76$ \\
\hline & & Green & $24.33(10.97)$ & 2 & 0.23 & .84 & 0.14 & $-2.91,51.57$ \\
\hline \multirow[t]{2}{*}{108} & 23.91 & Red & $22.87(1.88)$ & 25 & -2.81 & .009 & -0.55 & $22.11,23.63$ \\
\hline & & Green & $22.74(2.11)$ & 25 & -2.84 & .009 & -0.56 & $22.89,23.59$ \\
\hline
\end{tabular}

Note: Hypothesized population mean, $\mu$, is the midpoint of mean stable stop times obtained from FI 10s and FI 20 s terminal links in initial rapid acquisition. TL stands for terminal-link stimulus. Mean stop times are those obtained in the stable sessions of the uniform condition for the specified terminal-link stimulus. 
Table 4

\begin{tabular}{lllllll} 
& \multicolumn{7}{c}{ Block } \\
\cline { 2 - 7 } Pigeon & 1 & 2 & 3 & 4 & 5 & 6 \\
\hline \multicolumn{7}{c}{ Rapid Acquisition } \\
105 & 0.31 & $0.43^{*}$ & 0.26 & $0.37^{*}$ & 0.08 & 0.33 \\
106 & 0.10 & 0.14 & 0.17 & 0.01 & 0.01 & $0.57^{* *}$ \\
108 & 0.01 & 0.22 & 0.12 & $0.46^{* *}$ & 0.13 & $0.39^{*}$ \\
\hline \multicolumn{7}{c}{ Uniform } \\
105 & 0.03 & 0.17 & 0.01 & 0.34 & 0.29 & 0.26 \\
106 & 0.16 & -0.12 & $0.44^{*}$ & 0.12 & -0.07 & 0.12 \\
108 & 0.03 & -0.15 & -0.02 & 0.17 & 0.03 & 0.05 \\
\hline \multicolumn{7}{c}{ Rapid Acquisition Reversal } \\
105 & 0.34 & 0.33 & $0.41^{*}$ & $0.37^{*}$ & $0.37^{*}$ & 0.28 \\
106 & 0.17 & $0.47^{* *}$ & $0.40^{*}$ & $0.42^{*}$ & $0.55^{* *}$ & 0.10 \\
108 & $0.48^{* *}$ & 0.18 & -0.10 & 0.17 & $0.41^{*}$ & 0.29 \\
\hline
\end{tabular}

Note. Correlations were computed between residuals from regressions of log initial-link response ratios and log stop time ratios on log terminal-link immediacy ratios. Correlation coefficients are shown for individual pigeons for each session block as listed. ${ }^{*} \mathrm{p}<.05 .{ }^{* *} \mathrm{p}<.01$. 


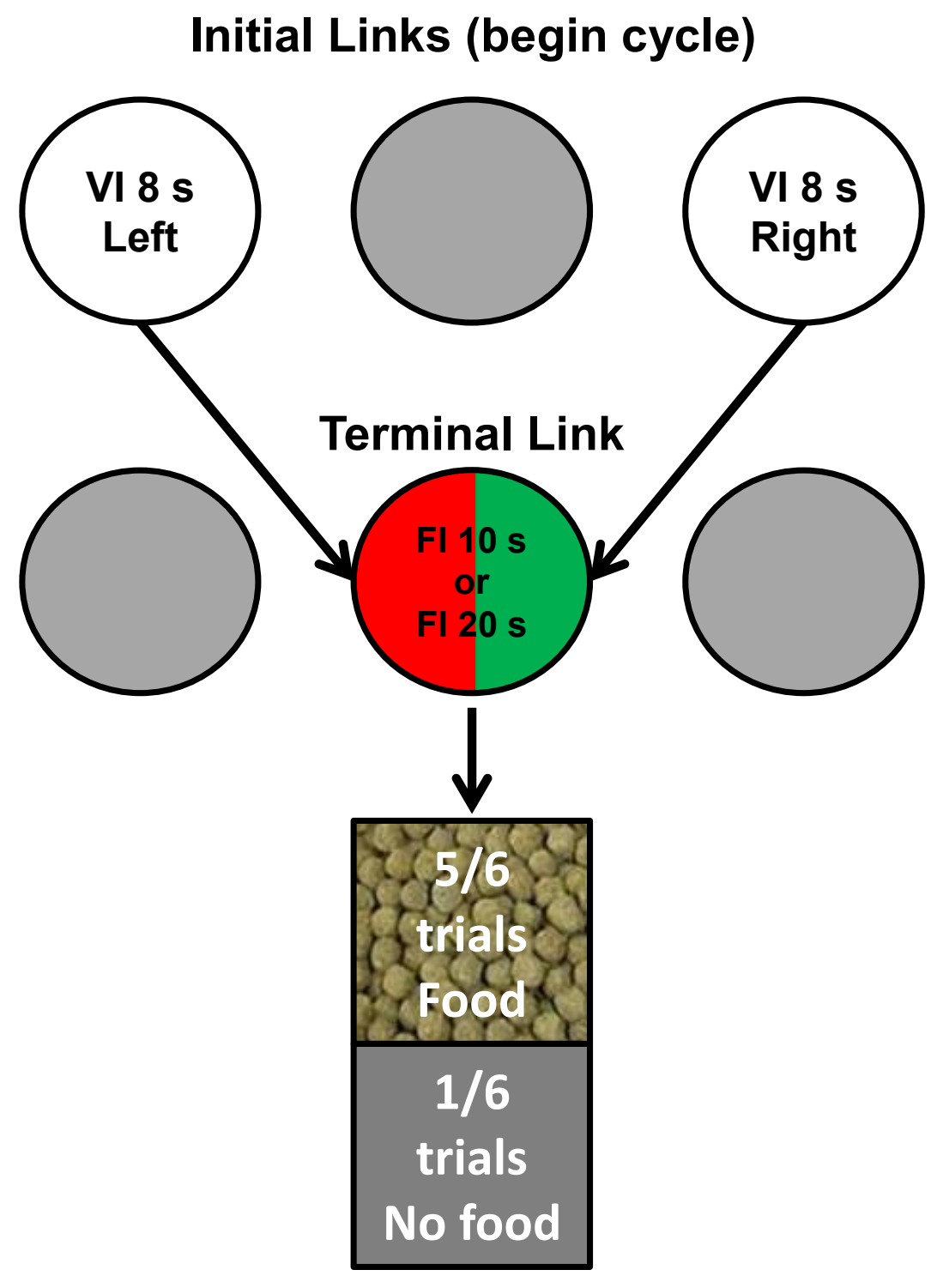

\section{End of Cvcle}

Figure 1. Diagram of the concurrent-chain procedure for the rapid-acquisition condition. Circles represent keys. Squares represent the end of the cycle. White side keys are VI 8 s initial links, red and green center key represents FI terminal links, with the red terminal link resulting from the left initial link and the green terminal link resulting from the right initial link. Terminal links resulted in food in 5/6 cycles and no food in the other $1 / 6$ cycles. 


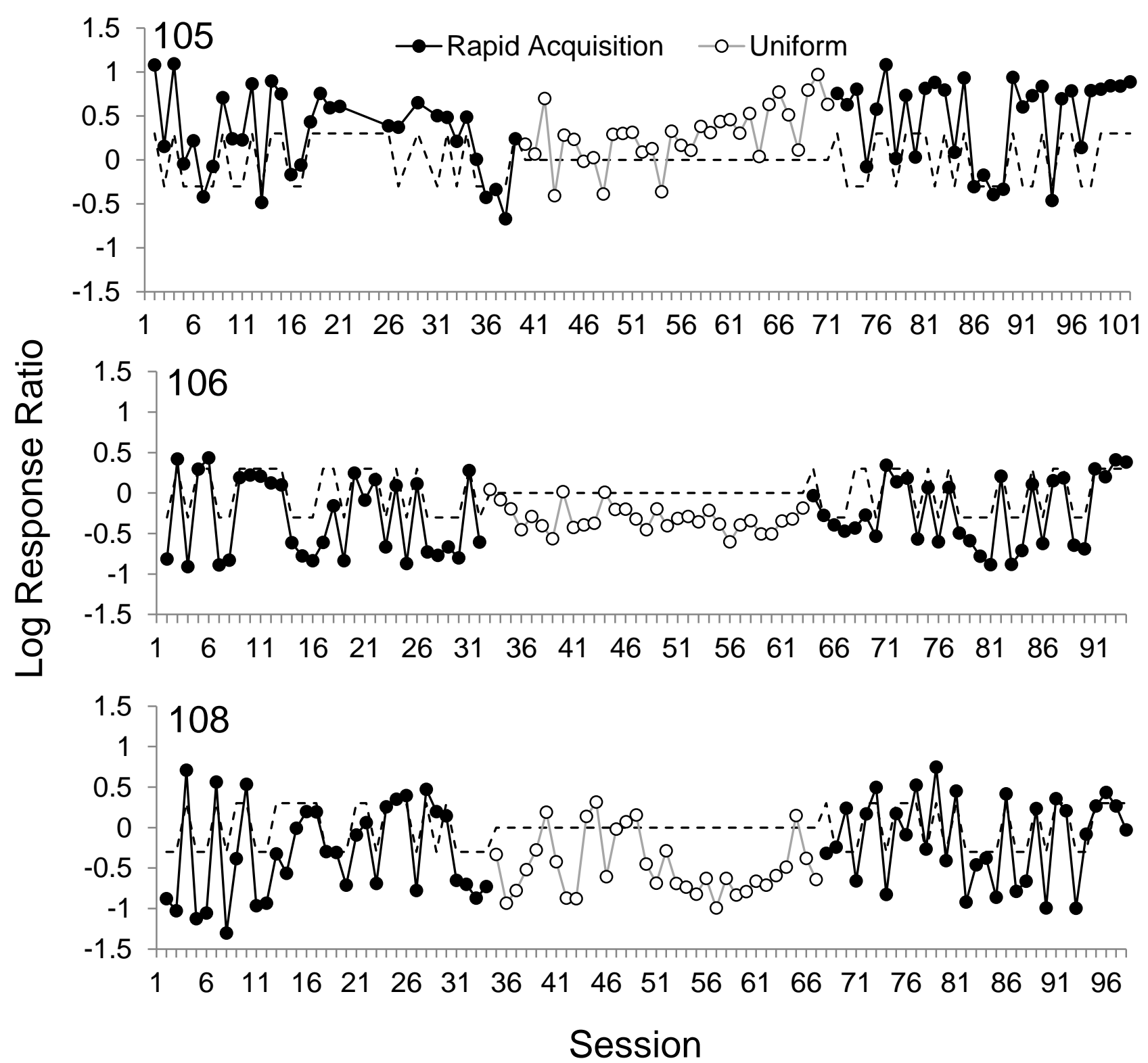

Figure 2. Log response ratios in the second half of sessions (blocks 4-6). Filled circles are rapid acquisition and unfilled circles are the uniform condition. The dashed line represents the programmed log immediacy ratio. 


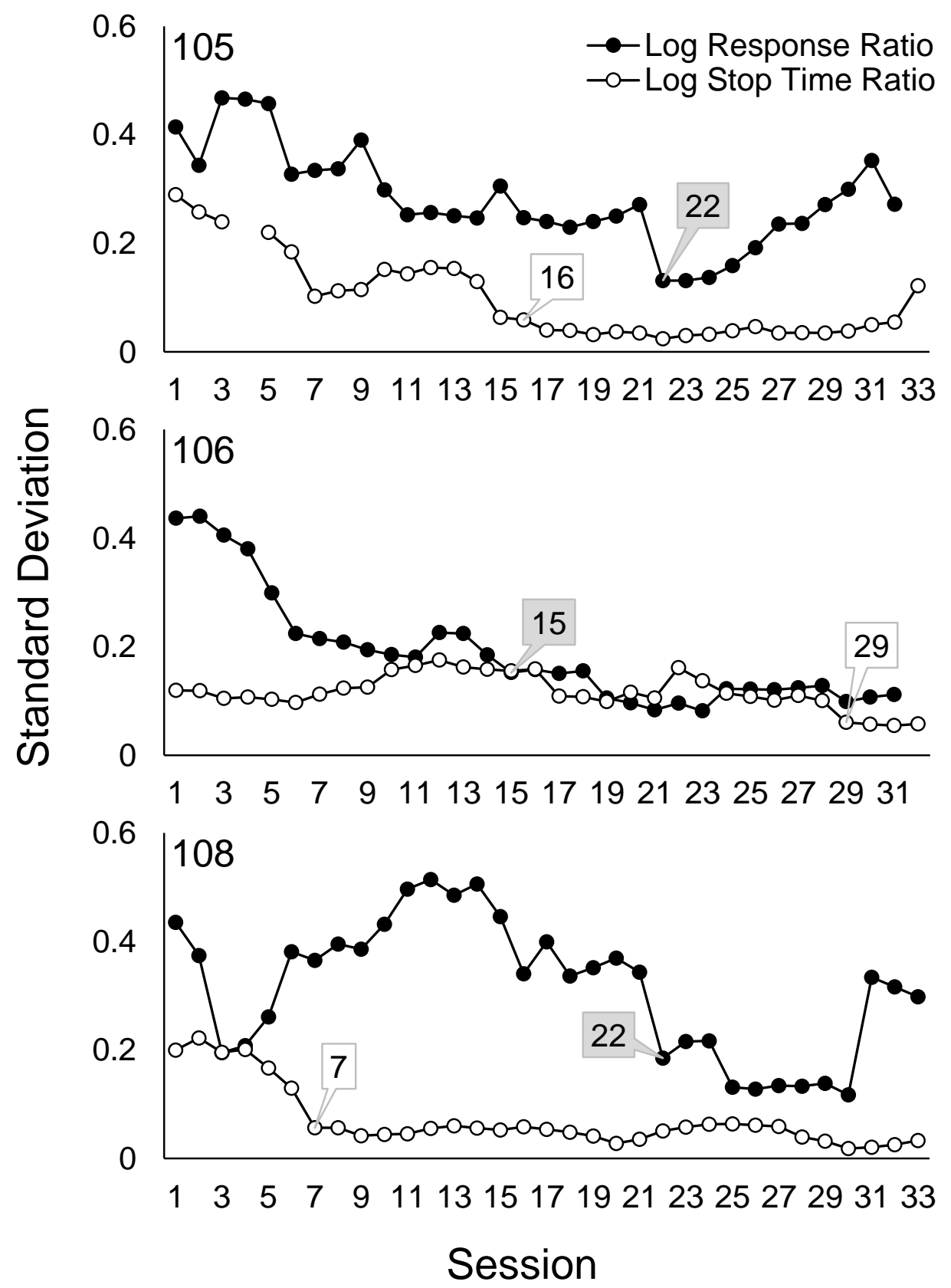

Figure 3. Moving average standard deviations of log response ratios (filled circles) and log stop time ratios (unfilled circles) from the session shown and six previous sessions for individual pigeons in the uniform condition. The session in which log response ratios and log stop time ratios stabilized is labeled using filled (log response ratio) and unfilled (log stop time ratio) data labels. 


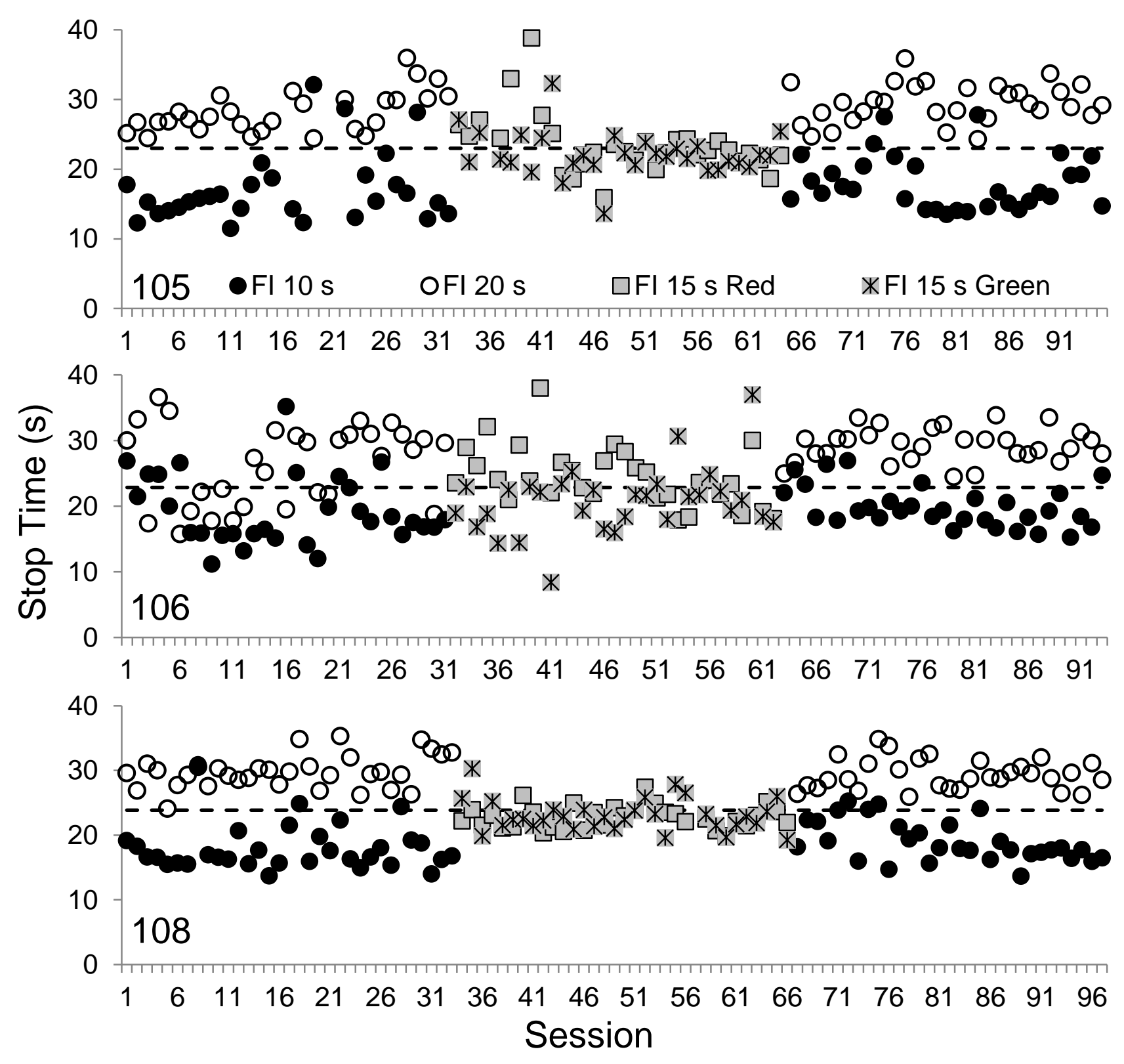

Figure 4. Stop times from the second half of sessions from rapid-acquisition and uniform conditions. Black and white circles represent terminal-link stimuli that correlated with the FI $10 \mathrm{~s}$ and FI 20 s schedules. Grey squares represent terminal-link stimuli associated with FI $15 \mathrm{~s}$ schedule. Asterisks denote green terminal links in the uniform condition. The dashed line represents an intermediate stop time calculated by averaging stop times in the second half of sessions in the first rapid-acquisition condition. 


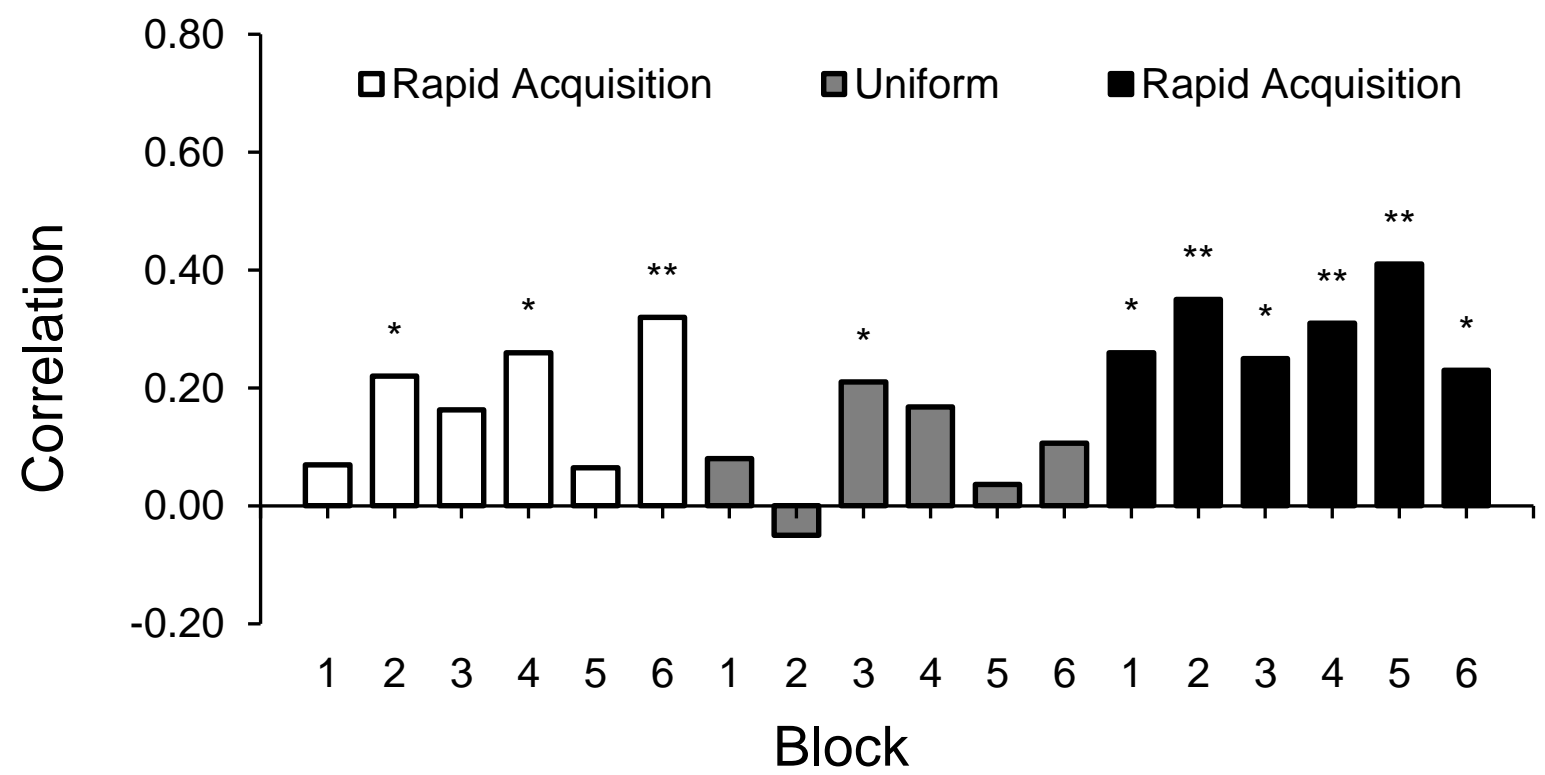

Figure 5. Pooled correlations of $\log$ response ratio and $\log$ stop-time ratio residuals as a function of session block (1-6). White and black bars represent the rapid-acquisition conditions and grey bars represent the uniform condition. Statistically significant correlations are denoted with asterisks $(*$ is $p<.05, * *$ is $p<.01)$. 


\section{Appendix A}

Stability Analyses for Rapid Acquisition

\section{Initial-Link Response Allocation}

To determine whether initial-link responding stabilized in the rapid-acquisition condition, Equation 2 was fit to data for individual pigeons for each block of 12 initial- and terminal-link cycles in a session. Estimates of sensitivity (unstandardized regression coefficients) were obtained from each regression. Averaged across pigeons, sensitivity values for the first rapidacquisition condition were 0.10 (SE 0.07), $0.69(0.15), 1.13(0.19), 1.32(0.10), 1.48(0.04)$, and $1.45(0.18)$ for the six blocks, respectively. For the second rapid-acquisition condition, sensitivity values for the six blocks were 0.15 (SE 0.10), $0.62(0.24), 0.86(0.05), 1.03(0.12), 1.26(0.18)$, and 1.26 (0.06). Two repeated-measures analyses of variance (ANOVA) with session block as the factor revealed that sensitivity differed across block in the first, $F(5,10)=27.66, p<.001$,

$\eta_{p}{ }^{2}=0.96$, and second, $F(5,10)=11.21, p<.001, \eta_{p}{ }^{2}=0.85$, rapid-acquisition conditions. Pairwise comparisons indicated that sensitivity stabilized in the second half of sessions (blocks 4- 6), a within-session acquisition trajectory found in previous research on the rapid-acquisition procedure (Kyonka \& Grace, 2007, 2008, 2010).

Equation 3 was fit to rapid-acquisition log response ratios for each session block up to two Lags for each individual pigeon. The Lag regression confirmed that response allocation was controlled by current-session immediacy. Figures A1 and A2 show unstandardized coefficients (i.e., sensitivity parameters) as a function of session block for Lag 0, Lag 1, and Lag 2 for the first and second rapid-acquisition conditions. During the first session block, sensitivity to immediacy was low and similar across Lags. Sensitivity increased for the current session (Lag 0) and decreased or remained the same for previous sessions (Lags 1 and 2) as exposure to the 
current immediacy ratio increased. By the sixth session block, log response ratios in the current session were a function of log immediacy ratios in the current session, with little to no dependence on the previous-session immediacy of reinforcement. Figure A3 shows log response ratios as a function of session block for each individual pigeon in both rapid-acquisition conditions. At the beginning of sessions, pecking was indifferent between left and right initial links. By the second half of sessions, log response ratios favored the initial link leading to the shorter terminal link. This acquisition trajectory is repeated in Figure A4, showing the correlations between log response ratios and log immediacy ratios for each cycle of initial and terminal links in rapid acquisition. Correlations were small and unsystematic in the beginning of sessions and reached their highest point by the second half of sessions for all pigeons. These findings were not surprising given data from previous rapid-acquisition research (Kyonka \& Grace, 2007, 2008, 2010).

\section{Terminal-Link Stop Times}

To confirm that stop times were stable within sessions in rapid acquisition, stop times for each block were regressed on terminal-link delays using a version of Equation 2. Like stability analyses for log response ratios, the sensitivity coefficients obtained from each regression of stop times on terminal-link delays were entered into repeated-measures ANOVAs with block as the factor. Averaged across subjects, sensitivity values in the first rapid-acquisition condition were 0.25 (SE 0.06), $0.63(0.18), 0.83(0.15), 1.03(0.09), 0.99(0.10)$, and $0.98(0.13)$ for the six blocks, respectively. For the second rapid-acquisition condition, sensitivity values for the six blocks were 0.25 (SE 0.04), 0.63 (0.05), 0.79 (0.13), 0.97 (0.04), 1.05 (0.07), and $1.10(0.09)$. Sensitivity values were entered into repeated-measures ANOVAs with Block as the factor. ANOVA revealed that sensitivity to FI delays differed across block in the first, $F(5,25)=16.18$, 
$p<.001, \eta_{p}{ }^{2}=.76$, and second, $F(5,25)=24.38, p<.001, \eta_{p}{ }^{2}=.83$, rapid-acquisition conditions. Pairwise comparisons indicated that sensitivity of stop times to terminal-link delays stabilized in the second half of sessions (blocks 4-6) in a manner similar to log response ratios.

To confirm that stop times were controlled by current-session (Lag 0) delays, a Lag regression analysis (up to 3 session Lags) was conducted as previously described for log response ratios. The B and C panels of Figures A1 and A2 show sensitivity parameters obtained from multiple regressions of stop time on current- and previous-session terminal link delays (up to Lag 2) for the red and green terminal links. For two pigeons (105 and 108), sensitivity increased for the current session $(\operatorname{Lag} 0)$ and decreased or remained the same for previous sessions (Lags 1 and 2) as exposure to the current immediacy ratio increased. Overall, stop times were more sensitive to the programmed terminal-link FI schedule value in the second half of sessions than in the beginning of sessions. For Pigeon 106, Lags 1 and 2 sometimes served as predictors of current-session stop times, but Lag 0 delays were the best predictor of stop times by the last session block for both rapid-acquisition conditions. 

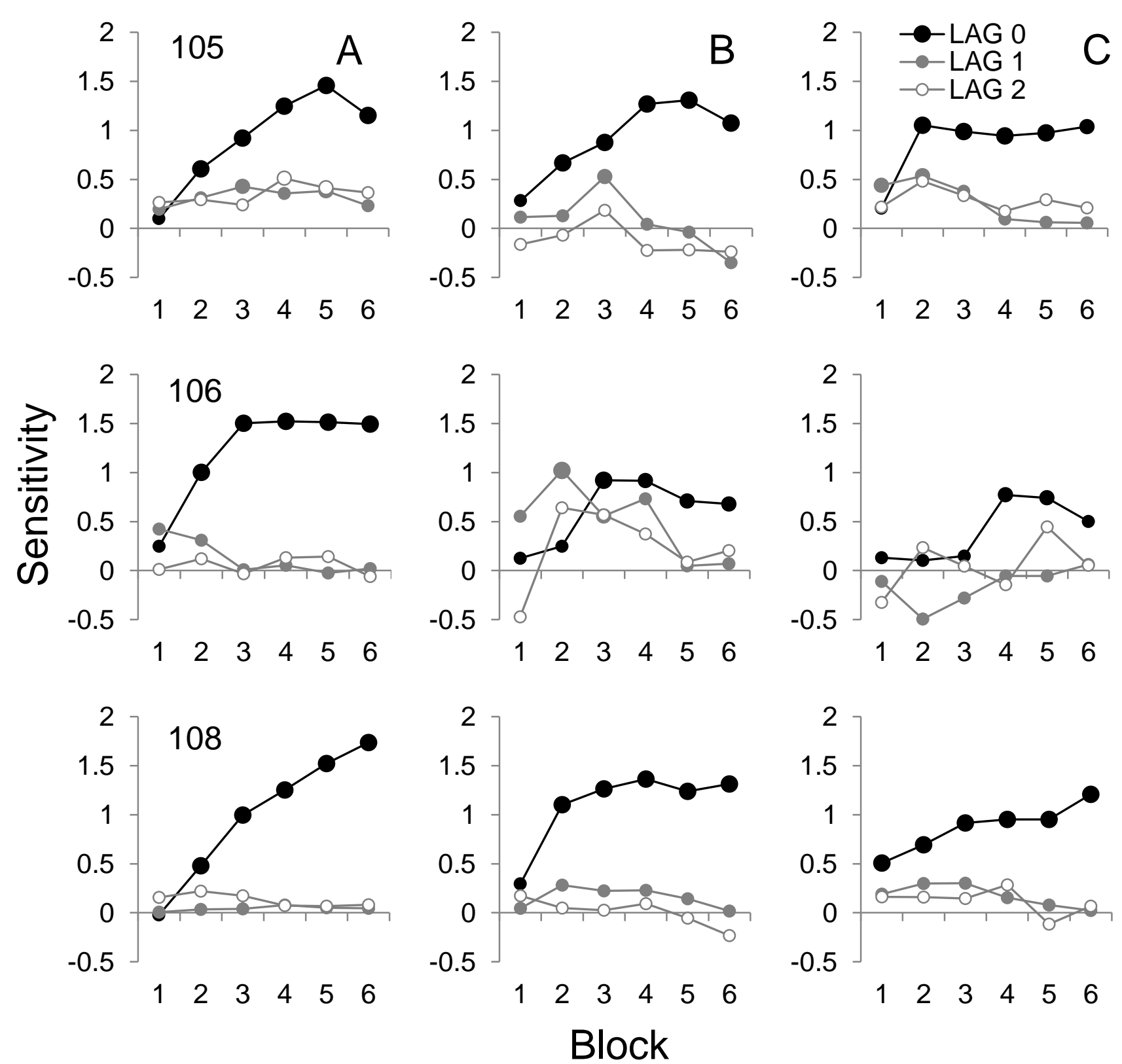

Figure A1. Sensitivity of log initial-link response ratio to relative immediacy (A), sensitivity of stop times from red no-food terminal links to red terminal-link delay (B), and sensitivity of stop times from green no-food terminal links green terminal-link delay $(\mathrm{C})$ as a function of session block for the current session (Lag 0), previous session (Lag 1), and second previous session (Lag 2) in initial rapid acquisition. Largest data points represent statistically significant prediction (largest to smallest $p<.01, p<.05$ and $p>.05$ ). 


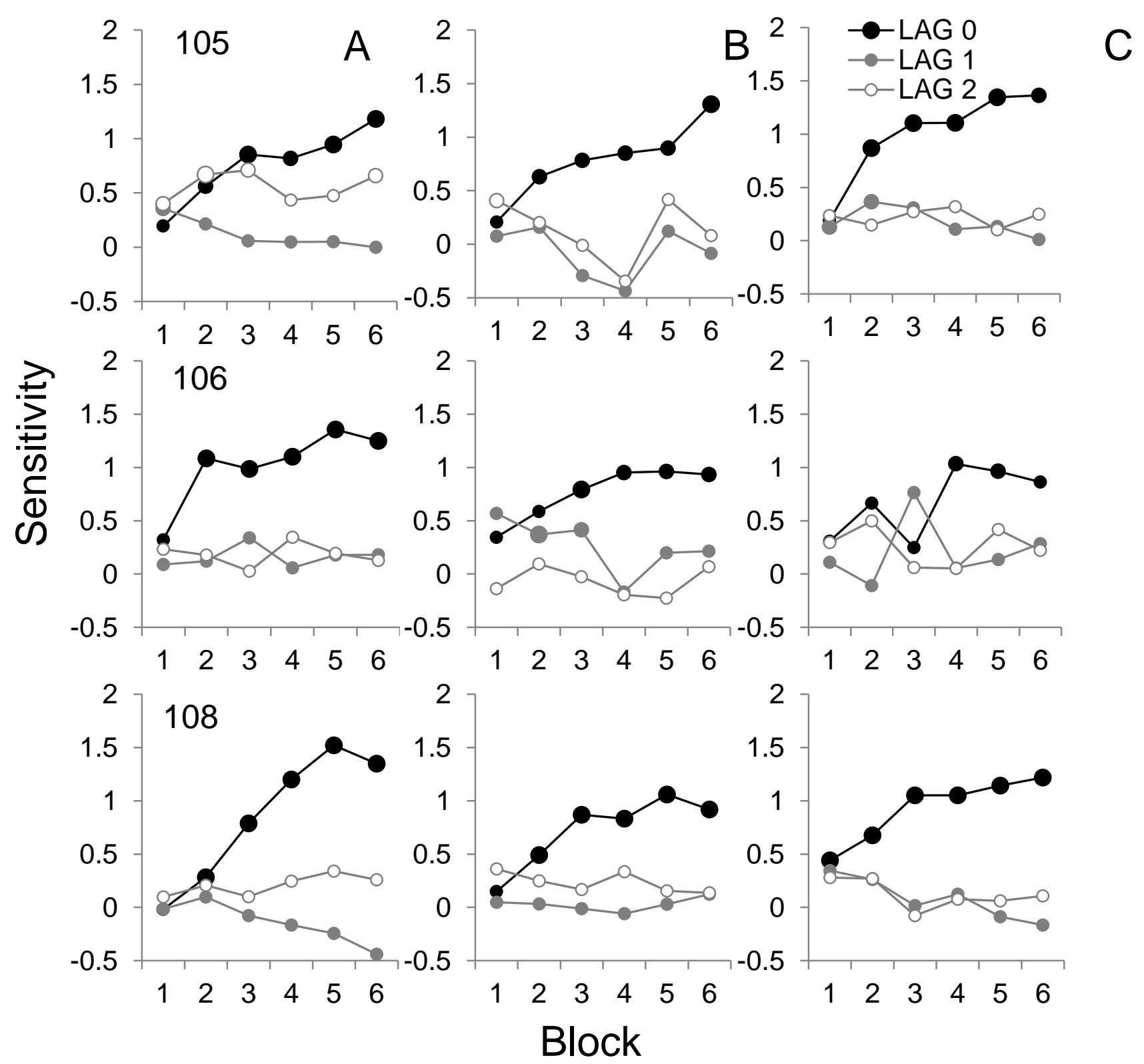

Figure A2. Sensitivity of log initial-link response ratio to relative immediacy (A), sensitivity of stop times from red no-food terminal links to red terminal-link delay (B), and sensitivity of stop times from green no-food terminal links green terminal-link delay $(\mathrm{C})$ as a function of session block for the current session (Lag 0), previous session (Lag 1), and second previous session (Lag 2) in the rapid-acquisition reversal. Largest data points represent statistically significant prediction (largest to smallest $p<.01, p<.05$ and $p>.05$ ). 


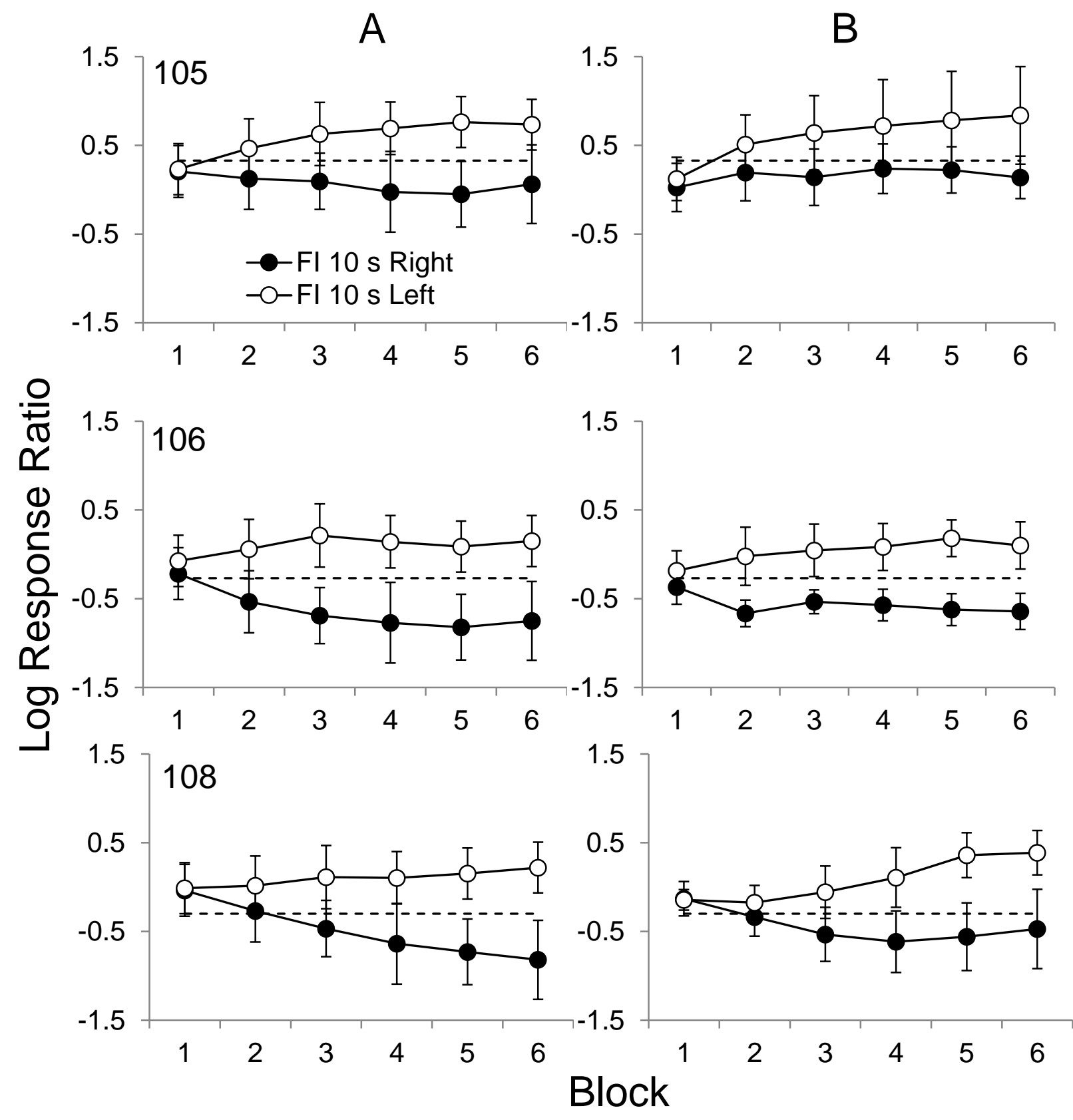

Figure A3. Log response ratios toward the initial link associated with the shorter (10 s) terminal link as a function of blocks of 12 trials within a session during the first (A) and second (B) rapidacquisition conditions. Open circles denote the left initial link and filled circles denote the right initial link. The dashed line represents individually determined indifference points obtained prior to the experiment. Error bars represent standard deviation. 


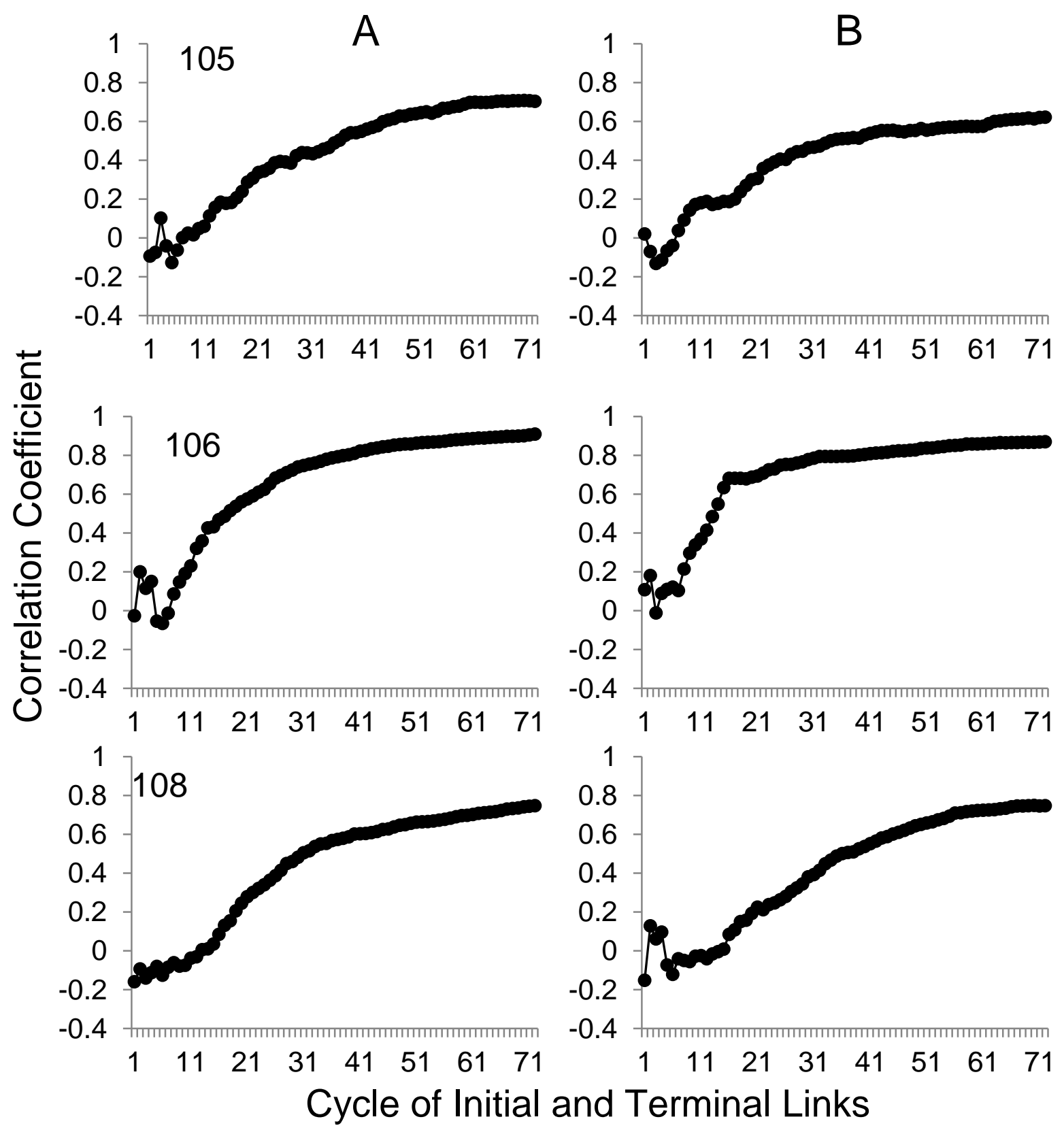

Figure A4. Correlation coefficients of log initial-link response ratios and log terminal-link immediacy as a function of cycles of initial and terminal links within a session in the first (A) and second (B) rapid-acquisition conditions. 


\section{Appendix B}

\section{Change-Point Analysis}

In dynamic environments, the trajectory of within-session adjustment of response allocation can be gradual or abrupt depending upon the temporal resolution with which it is viewed. Kyonka and Grace (2008) used a change point analysis to characterize within-session adjustment of response allocation in each cycle of initial and terminal links of concurrent chains. Cumulative pecks to the right key were presented as a function of the cumulative pecks to the left key for every initial link in a session. Linear and bilinear ("broken stick") models were then fit to the functions to identify whether response allocation changed at some point. For sessions characterized by the bilinear model, they used linear interpolation to estimate the cycle in the session (change point) in which a change in preference occurred. Change point analysis revealed that changes in response ratios were generally abrupt. Before change points, response allocation was relatively indifferent to the relative value of terminal links, but response allocation after change points favored the richer terminal link. In addition, change points were earlier in sessions when the value of terminal links was very different, and later when terminal-link values were similar.

\section{Data Analysis and Results}

To examine the pattern of within-session changes in response allocation in the initial links of rapid-acquisition and uniform conditions, a change point analysis was conducted. First, a cumulative-cumulative response plot was generated for each session with cumulative pecks to the right key plotted as a function of cumulative pecks to the left key during each initial link. Linear and bilinear ("broken stick") models were fit to the cumulative record for each session. A linear model described a session with no changes in response allocation, a bilinear model 
described a session where a shift in response allocation occurred, and when neither model fit the data adequately, many shifts in responding occurred (multiple change points). Session categorization (as linear, bilinear, or multiple) was based on visual inspection of cumulative response plots and statistically informed by an $F$ ratio and an acceptable significance level of $p<$ .05 in the comparison of linear and bilinear model fits.

Examples of the cumulative-cumulative response plots generated by the analysis are displayed in Figure B1. The top graph is an example of a bilinear session, the center a linear session, and the bottom graph is a session characterized by more than one change point (multiple). The change point in the bilinear model was the point in each session (expressed in units of left key pecks) of greatest change in response allocation.

To estimate whether the pattern of response allocation within sessions differed across conditions, characterizations of sessions were compared across rapid-acquisition and uniform conditions. Figure B2 shows the percentage of sessions described as having no change point (linear), one change point (bilinear), or multiple change points. For all pigeons, most sessions were characterized by the bilinear model in initial rapid acquisition (73.57\%) and fewer sessions were characterized as bilinear in the uniform condition (61.81\%). The percentage of sessions in which multiple change points were identified increased from initial rapid acquisition (12.64\%) to the uniform condition (26.43\%). Overall, $9.48 \%$ of sessions were characterized by the linear model in rapid acquisition; this percentage increased to $11.76 \%$ in the uniform condition. The increase in sessions characterized as having none or many change points in the uniform condition indicated disruption in the traditional rapid acquisition trajectory that persisted through a reversal back to rapid acquisition (59.14\% of sessions were bilinear in the reversal). 
To identify whether the point at which a switch in response allocation (i.e., acquisition of preference) differed across conditions, change points from bilinear sessions were compared. Change points were unsystematically variable with means of $26.11(S E=1.63)$ in initial rapid acquisition, $29.02(S E=2.20)$ in the uniform condition, and $26.21(S E=2.06)$ in the return to rapid acquisition. There were no significant shifts in change points across conditions. Thus, with exposure to equivalent terminal links, the temporal location of the acquisition of preference, when it occurred, did not change. 


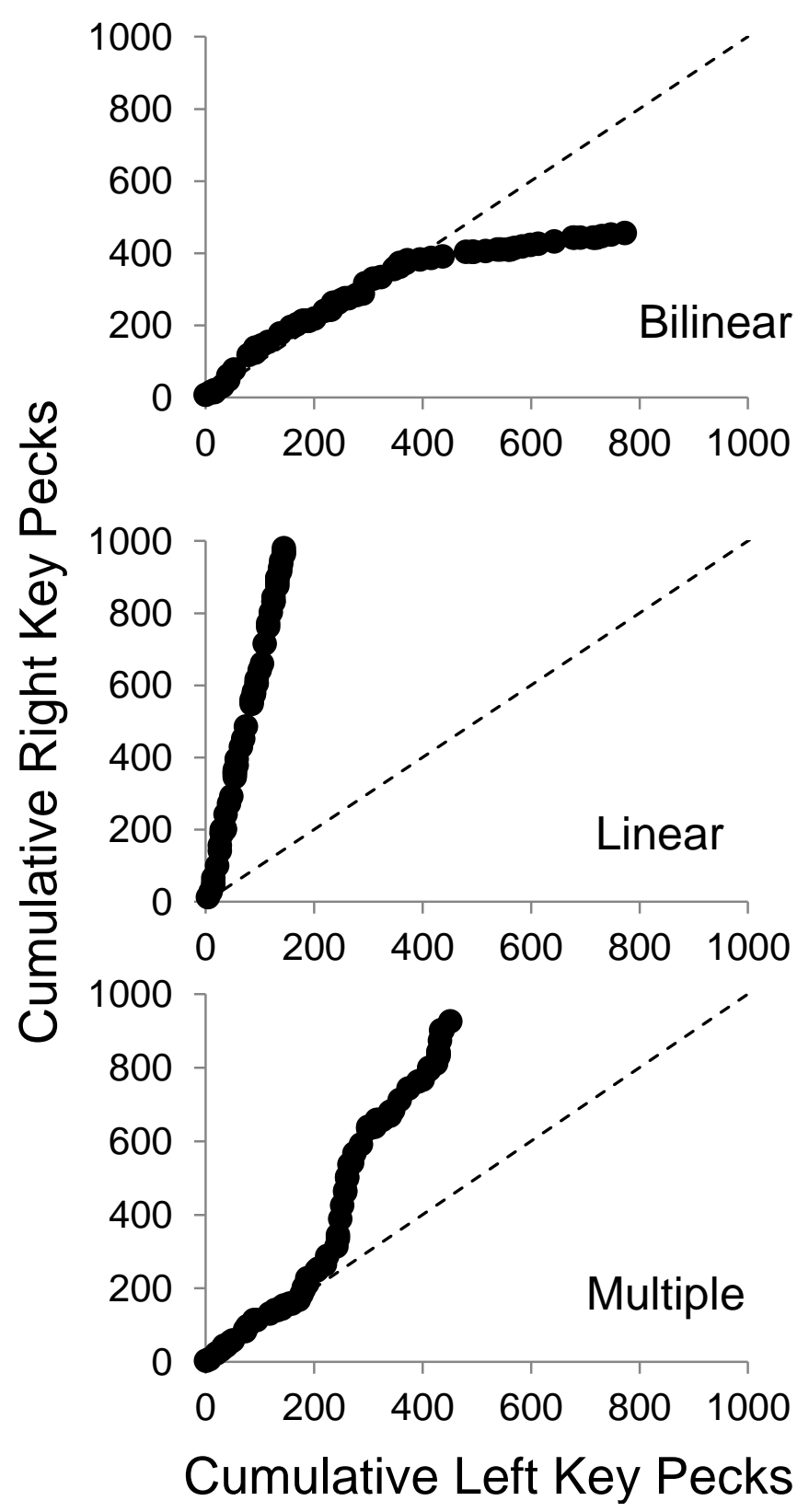

Figure B1. Cumulative right key pecks as a function of cumulative left key pecks representing a session categorized as bilinear (top), linear (center), and having multiple change points (bottom). 


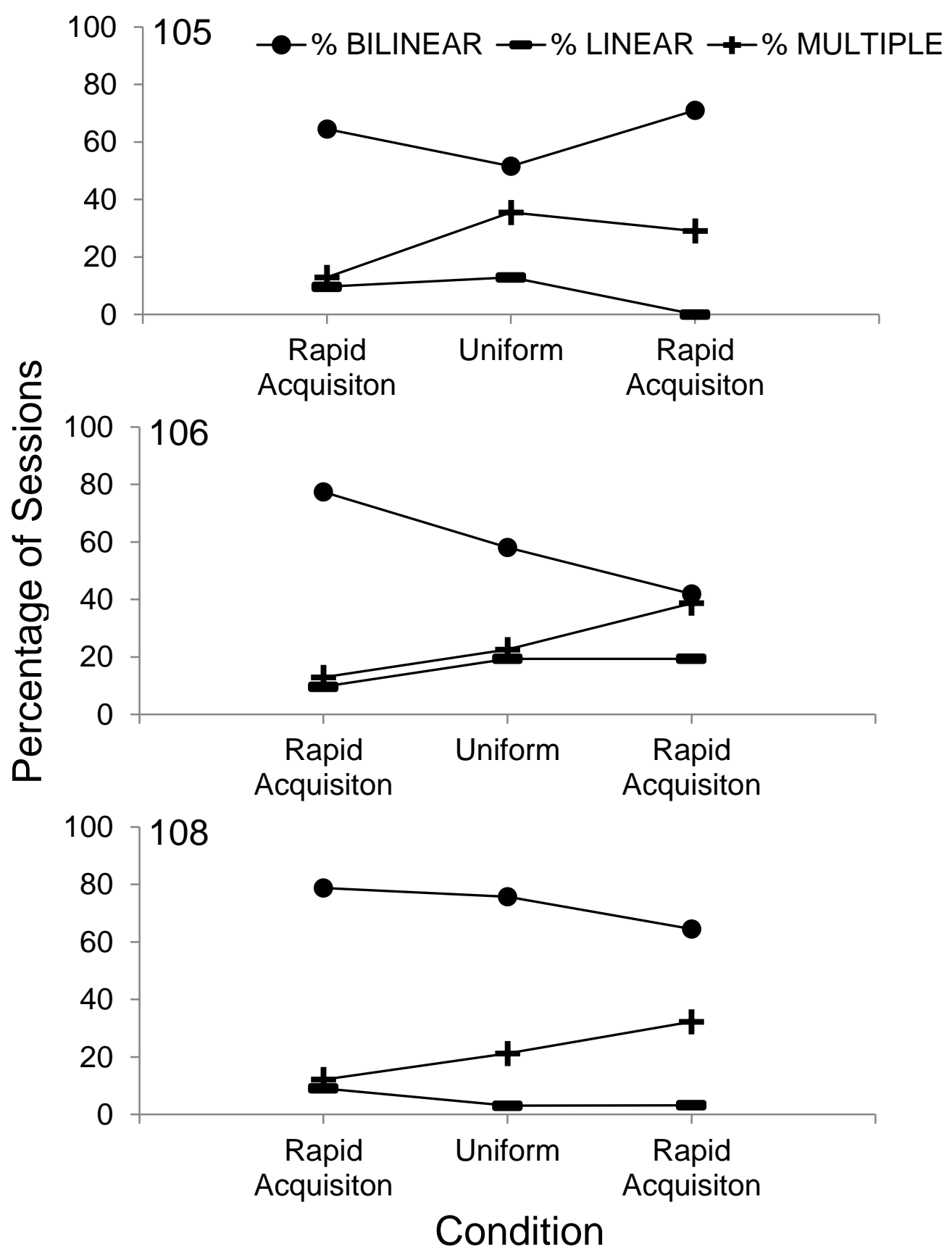

Figure B2. Percentage of sessions in rapid-acquisition and uniform conditions that were categorized as bilinear (circle), linear (horizontal line), or having multiple change points (plus). 